\title{
The Effectiveness of Cognitive-Behavioral Group Therapy on Symptoms of Depression and Anxiety in Women with Chronic Schizophrenia Admitted to Hejazi Hospital in Mashhad
}

\section{Masoud Kashani Lotfabadi ${ }^{1}$, Seyedeh Sara Aboozarian ${ }^{* 2}$, Maryam Farnosh ${ }^{3}$, Azam Mohammadi ${ }^{4}$, Bibi Maryam Hashemi ${ }^{5}$, Azam Salarhaji ${ }^{6}$}

1. Psychiatry and Behavioral Sciences Research Center, Ibn-Sina psychiatric Hospital, Mashhad University of Medical Sciences, Mashhad, Iran

2. Msc in Psychology, Payam Noor University of Garmsar, Garmsar, Iran

3. Msc in Counseling, Islamic Azad University of Quchan, Quchan, Iran

4. MSc in Psychiatric Nursing, Psychiatry and Behavioral Sciences Research Center, Ibne-Sina psychiatric Hospital, Mashhad University of Medical Sciences, Mashhad, Iran

5. Ms in Islamic Psychology, Payam Noor University of Gonabad, Gonabad, Iran

6. PhD Student in Nursing, Student Research Committee, Faculty of Nursing and Midwifery, Mashhad University of Medical Sciences, Mashhad, Iran

\section{Article Info}

Received: 2020/09/07;

Accepted: 2020/09/24;

Published Online: 2020/11/28

10.30699/ajnmc.29.2.146

Original Article

Use your device to scan and read the article online

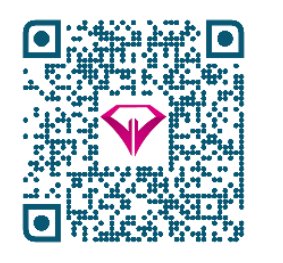

\section{ABSTRACT}

Introduction: Considering the negative effects of depressive symptoms and anxiety on the course of schizophrenia, it seems that the combination of cognitive-behavioral group therapy with self-care skills can increase the effectiveness of this treatment in reducing the distress of patients with chronic schizophrenia. Therefore, a study was designed and conducted to determine the effect of cognitive-behavioral therapy group of self-care skills on the symptoms of anxiety and depression in women with chronic schizophrenia.

Methods: This randomized controlled clinical trial was performed on 30 women with chronic schizophrenia admitted to Hejazi Psychiatric Hospital in Mashhad. The intervention group $(n=15)$ underwent cognitive-behavioral therapy group of self-care skills during 10 sessions of one and a half hours and the control group $(n=15)$ received a routine care. The data collection tool was the Hamilton Anxiety and Depression Scale which was completed in three stages. Data were analyzed using repeated measures analysis of variance and independent t-test.

Results: There was a significant decrease between the intervention and control groups in terms of changes in mean anxiety before and after the intervention $(P<0.001)$ but in terms of changes in mean anxiety before and six months after the intervention and changes in mean depression during the stages there was no significant difference $(P>0.05)$.

Conclusion: Cognitive-behavioral group therapy can be effective in reducing anxiety symptoms, but to increase the duration of its effect, the duration of sessions should be increased.

Keywords: Cognitive-behavioral therapy, Group therapy, Anxiety, Depression, Chronic schizophrenia

Corresponding Information:

Seyedeh Sara Aboozarian, Msc in Psychology, Payam Noor University of Garmsar, Garmsar, Iran. Email: Sara.Aboozarian@gmail.com

Copyright $($ C 2021, This is an original open-access article distributed under the terms of the Creative Commons Attribution-noncommercial 4.0 International License which permits copy and redistribution of the material just in noncommercial usages with proper citation.

How to Cite This Article:

Kashani Lotfabadi M, Aboozarian S S, Farnosh M, Mohammadi A, Hashemi B M, Salarhaji A. The Effectiveness of Cognitive-Behavioral Group Therapy on Symptoms of Depression and Anxiety in Women with Chronic Schizophrenia Admitted to Hejazi Hospital in Mashhad. Avicenna J Nurs Midwifery Care. $2021 ; 29$ (2) :146-159 
تأثير كروهدرمانى شناختىرفتارى مههارتهاى شناختىرفتارى بر علائم افسردگى و اضطراب زنان مبتلا به اسكيزوفرنى مزمن بسترى در بيمارستان حجازى مشهرد

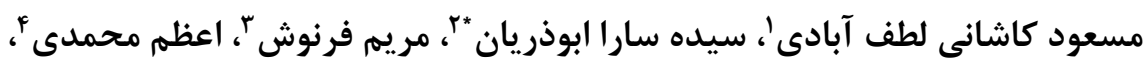

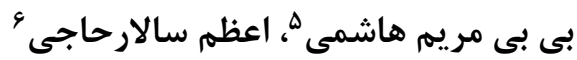

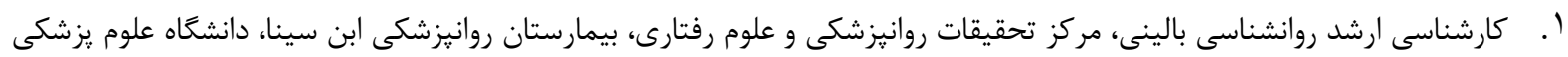
مشهد، مشهد، ايران

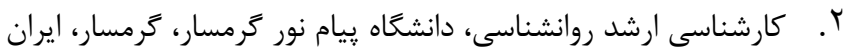

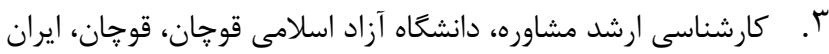

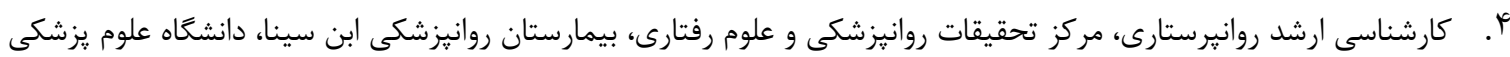
مشهد، مشهد، ايران

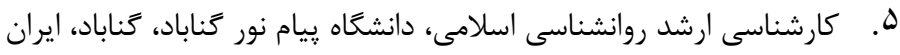

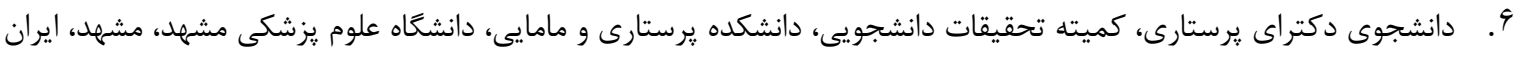

\begin{tabular}{|c|c|}
\hline جكيده & اطلاعات مقاله \\
\hline 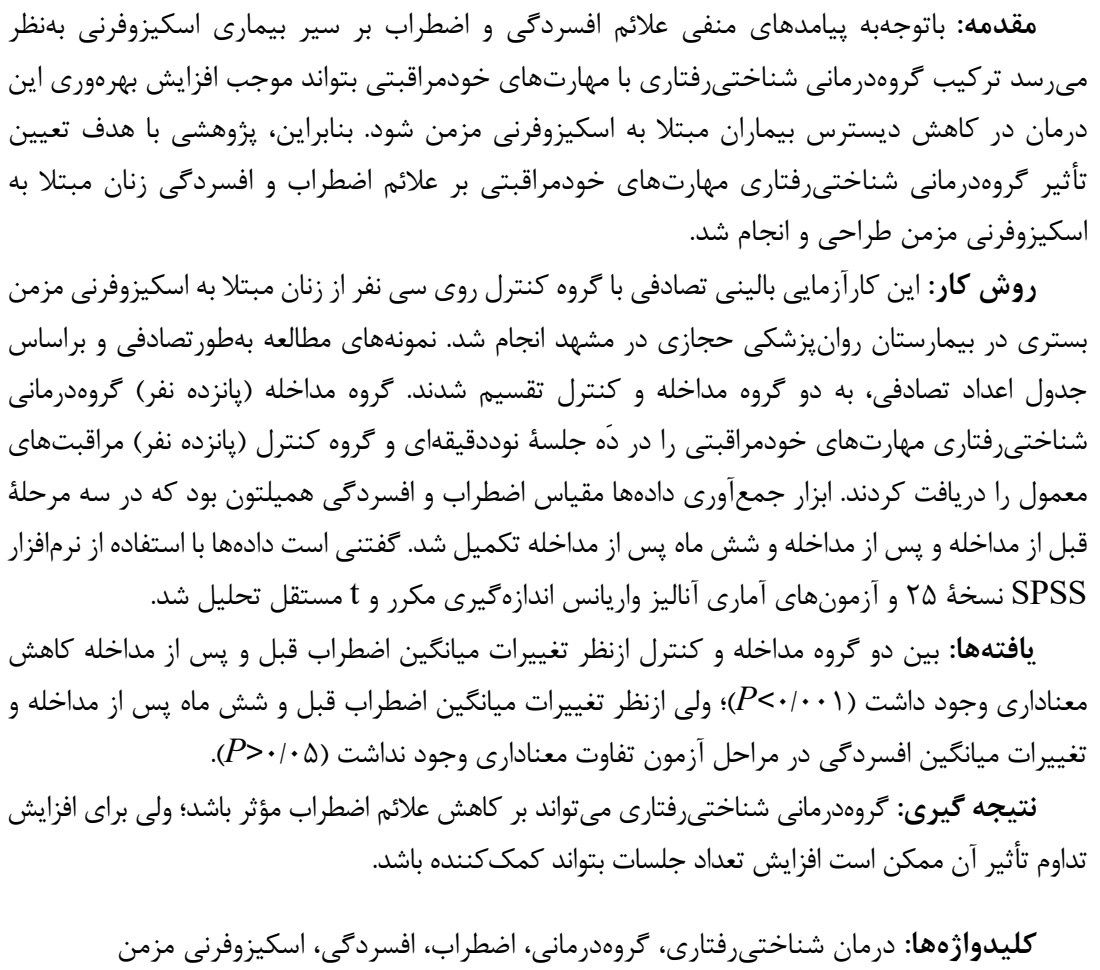 & براى دانلود اين مقاله، كد زير را با موبايل \\
\hline
\end{tabular}

مقله

و منطقهاى و جهانى تحميل مى كند [ [1]. اين بيمارى با طيف

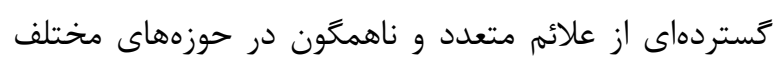
علائم مثبت (هذيان و توهم) و منفى (بىانگيزگى و بىارادىى)
اسكيزوفرنى اختلال عصبىروان يزشكى مزمن و بيجِيدهاى

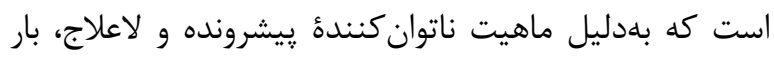

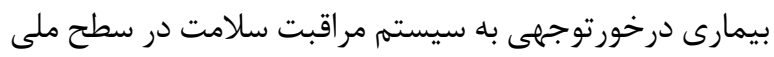


(شامل احساس ناميدى، گَناه، اضطراب درماندگى و افكار

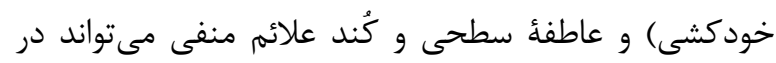

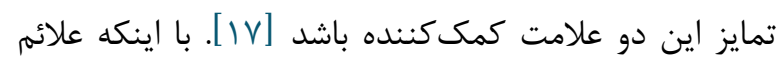

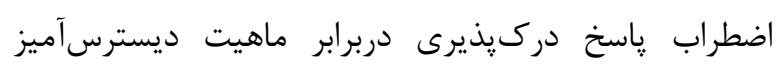

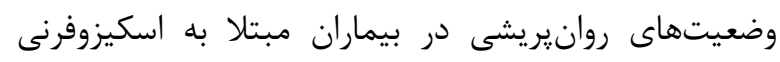

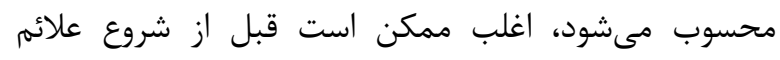

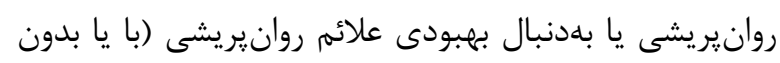

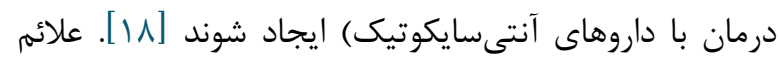

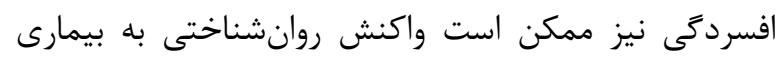

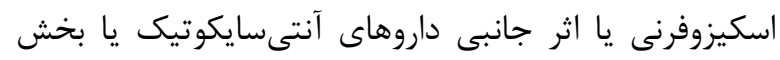

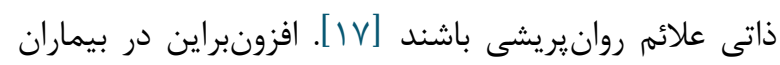

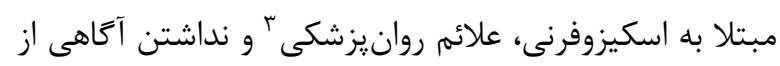

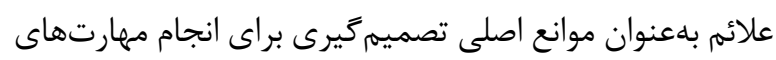

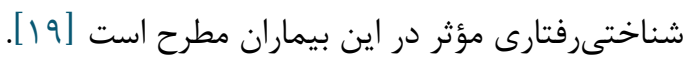

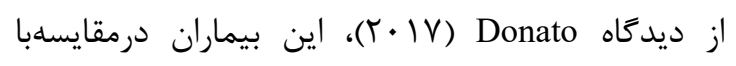

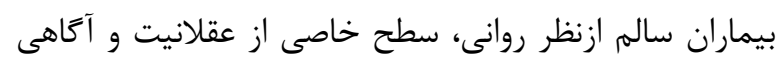

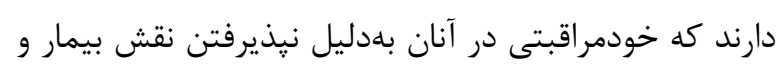

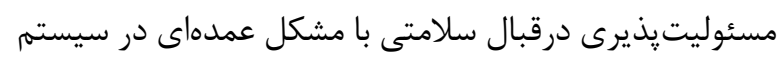

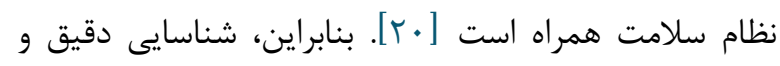

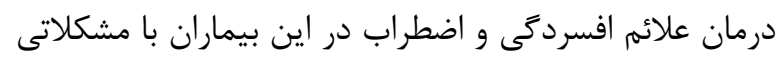

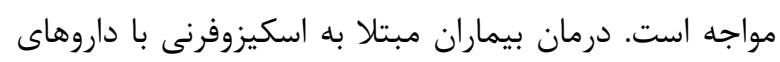

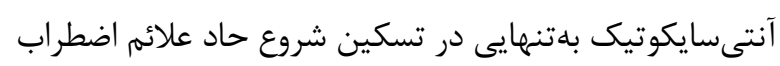

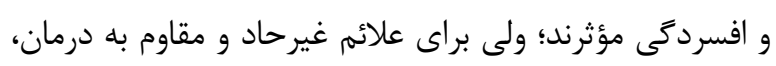

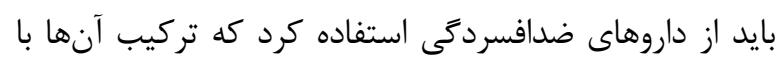

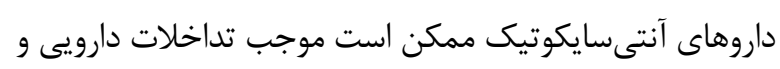

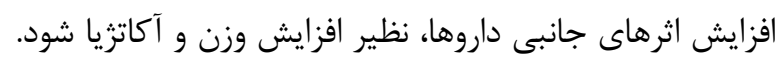

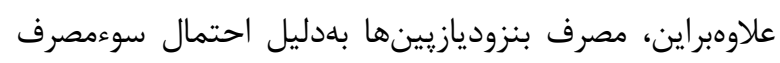

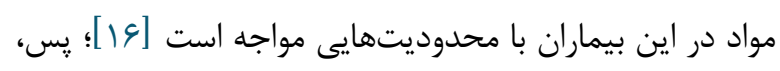

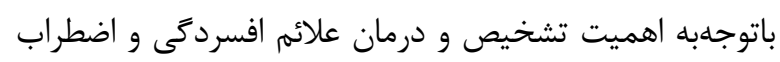

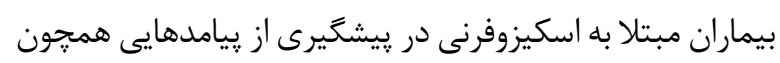

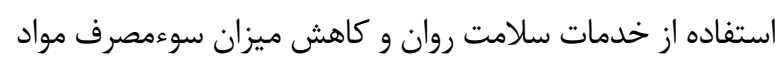

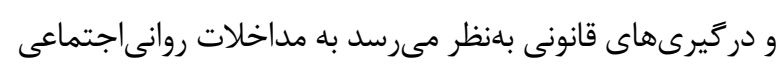

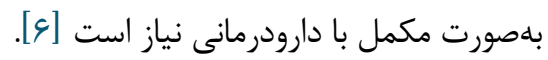

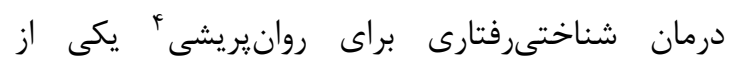

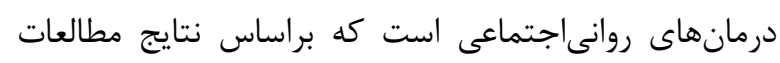

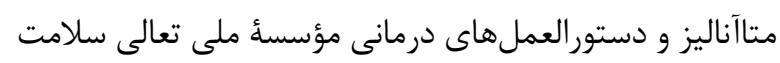

${ }^{3}$ psychiatric symptoms

${ }^{4}$ Cognitive behavioral therapy for psychosis (CBTp)
و عصبىشناختى و عاطفى (افسردگى و اضطراب) تظاهر

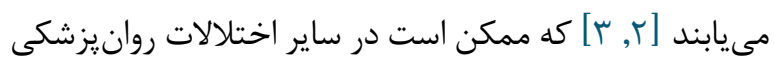

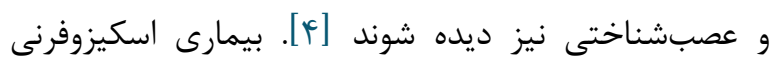

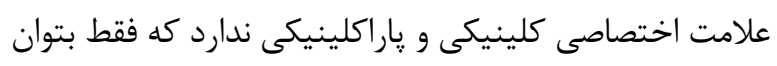

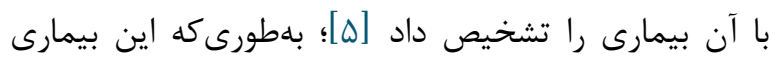

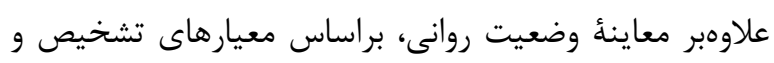

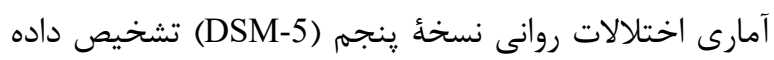

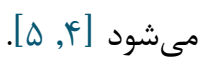
افسردگى و اضطراب از علائم رايج در بيماران مبتلا به

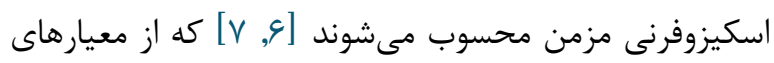

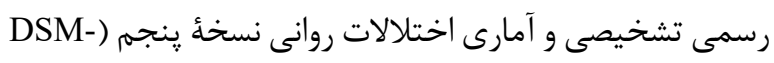
5) در تشخيص اسكيزوفرنى نيستند؛ ولى اغلب اين بيماران

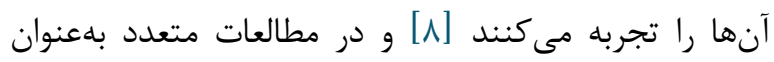

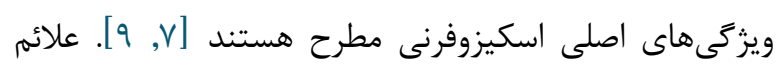

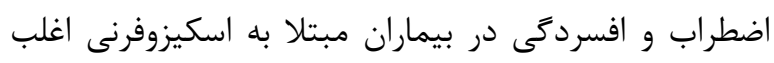

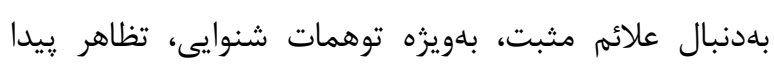

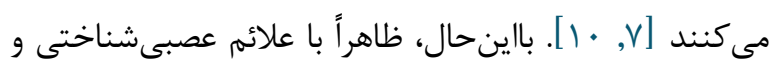

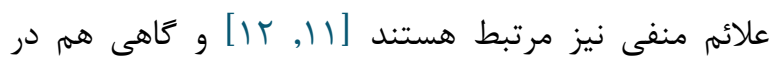

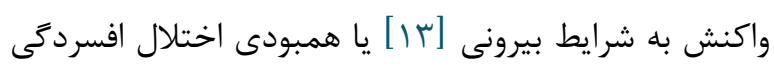

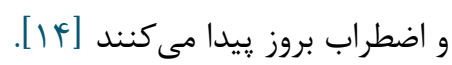

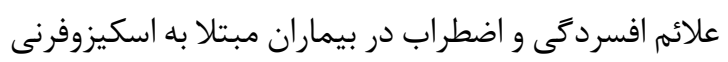

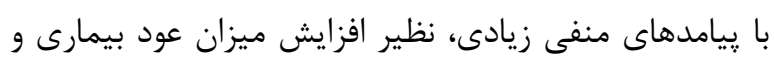

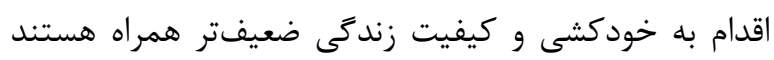

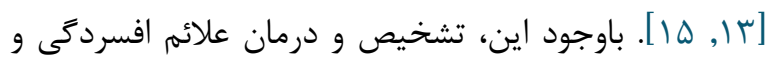

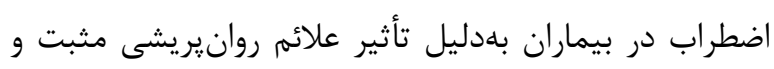

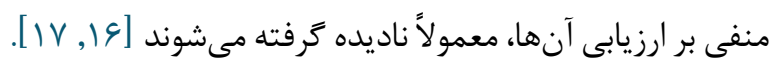

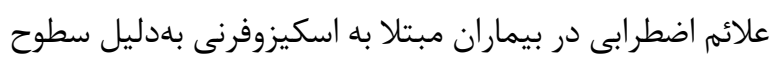

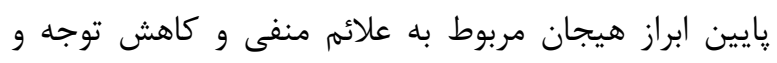

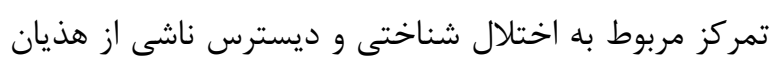

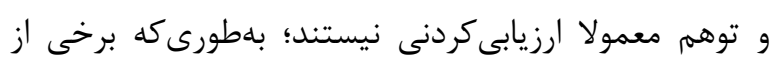

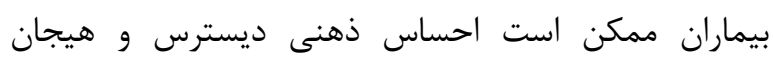

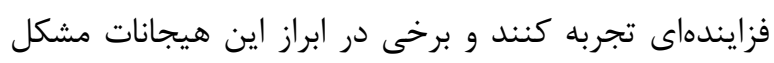
داشته باشند [19]. تمايز علائم افسردگى از علائم منفى بهدليل شباهتهاى التها.

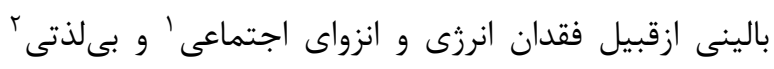

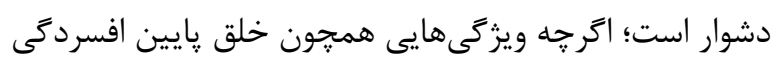

${ }^{1}$ Social withdrawal

${ }^{2}$ Anhedonia

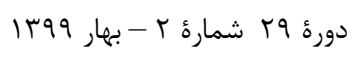


بين اعضا مبنىبر فراهم كردن حمايت افراد همتراز در مقابله

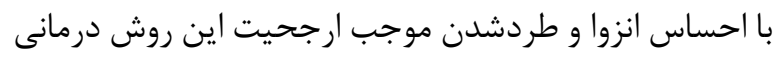
بر ساير روشهاى انفرادى مىشود و مقرونبهصرفه است

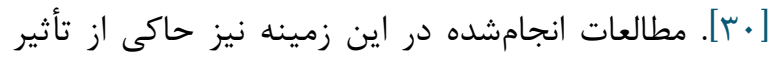
كروهدرمانى شناختىرفتارى بر مسائل روانشناختى بيماران

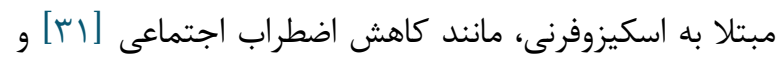

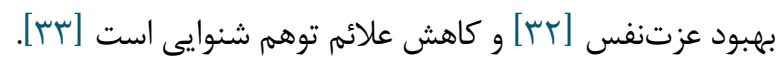
اغلب مطالعات به درمان شناختىرفتارى در بيماران مبتلا

به اسكيزوفرنى مبتنىبر علائم روانيريشى مربوط است و روى دئي

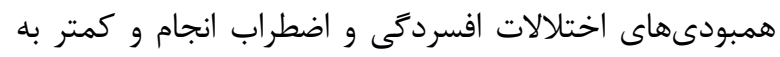

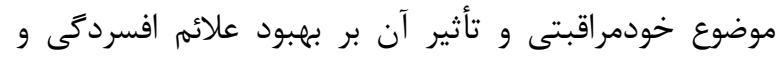

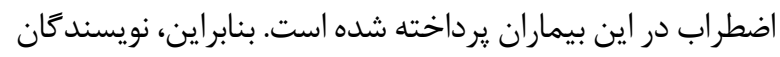

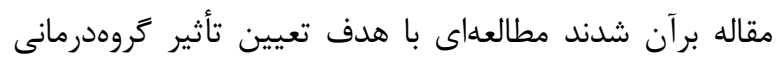

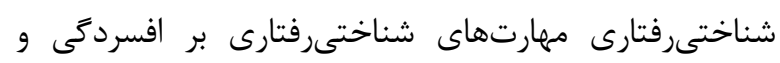
اضطراب زنان مبتلا به اسكيزوفرنى مزمن انجام دهند.

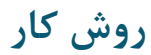

اين كارآزمايى بالينى تصادفى با تروه كنترل در سال

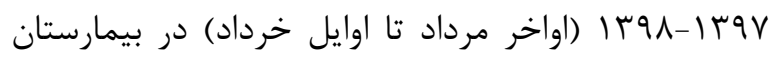

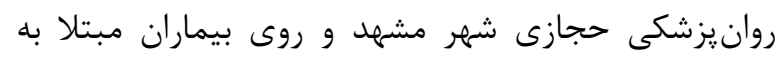

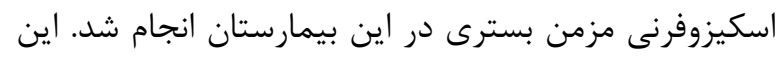
بيمارستان زيرنظر دانشعاه علوم يزشكى دئى مشهد و و عمدتاً محل

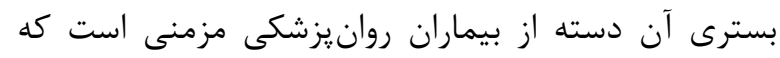
بهدلايل مختلف، مانند يسرفت اعمال شناختى و وجود علائم

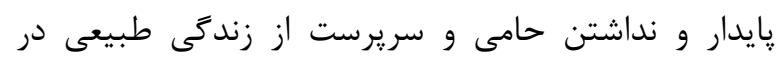

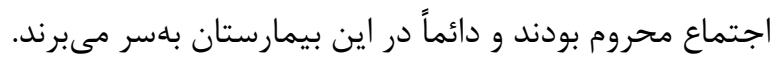
حجم نمونه براساس مطالعُ مقدماتى و با استفاده از فرمول

$$
\frac{\left(z_{1}-\alpha / 2+z_{1-\beta}\right)^{2}\left(\mathrm{~s}_{1}^{2}+\mathrm{s}_{2}^{2}\right)}{\left(\bar{x}_{1}-\bar{x}_{2}\right)^{2}}
$$

از طريق محاسبهُ ميانگين و انحرافِمعيار نمرهٔ كل

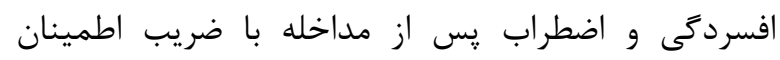

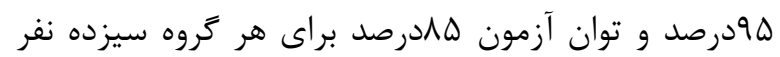

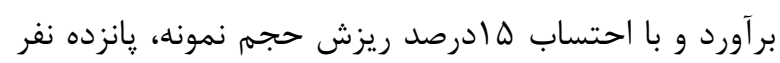

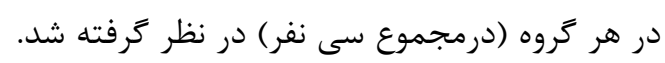

و مراقبت' در كانادا و انگلستان، بلهورت درمان الحاقى با دارودرمانى براى كاهش علائم روانيريشى و ديسترس ناشى از

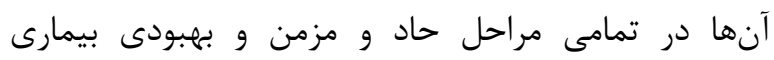

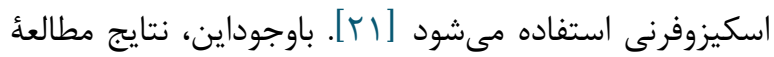

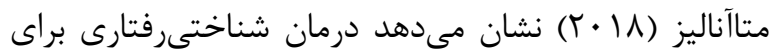

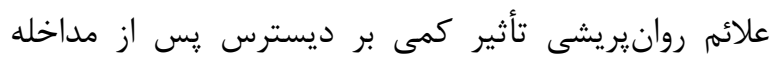

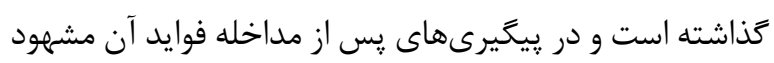

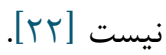

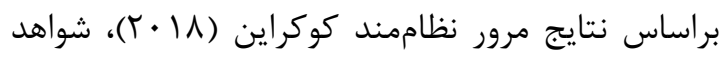

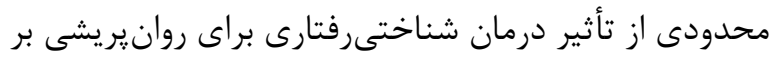

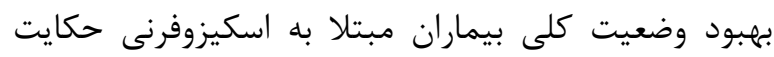

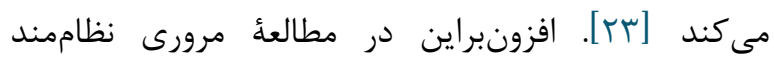

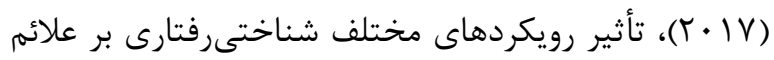

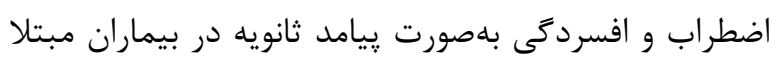

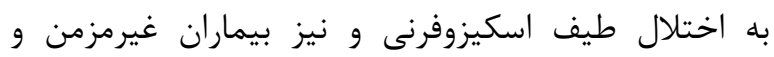

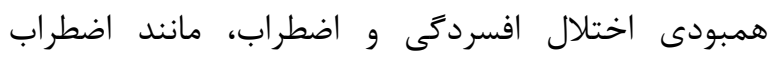

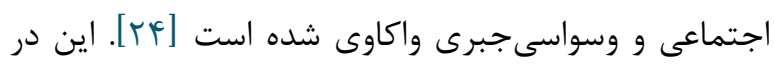

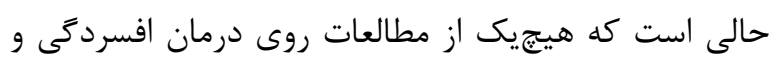

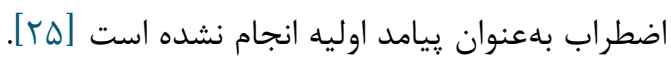

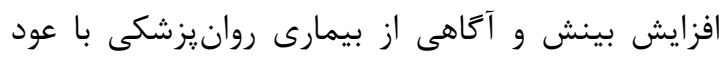

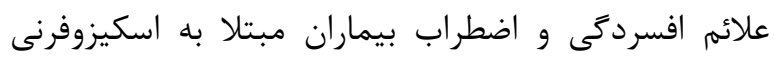

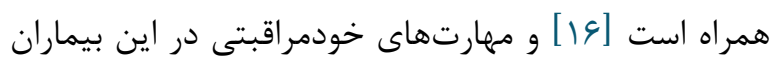

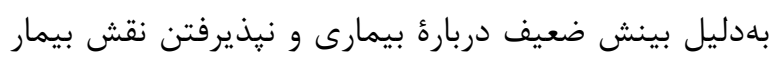

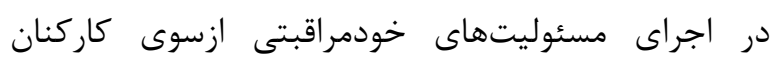

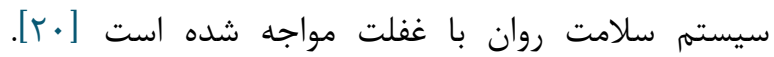

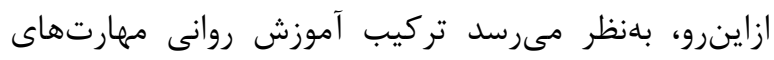

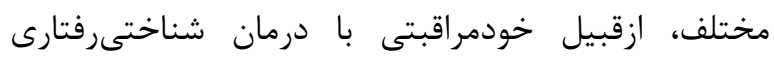

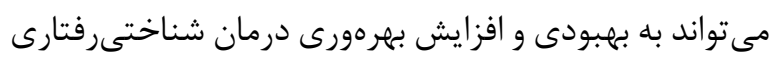

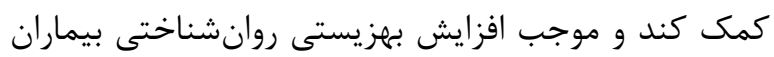

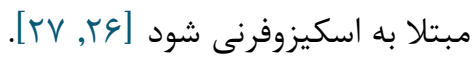

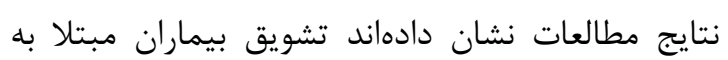
اختلالات روانيزشكى مزمن مىتواند موجب تقويت و بهكاركيرى مهارتهاى خودمراقبتى در اين بيماران شود

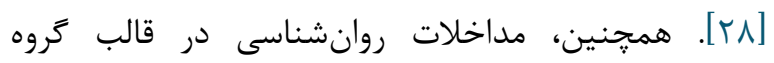
اثربخشى بيشترى در بيماران مبتلا به اسكيزوفرنى دارد

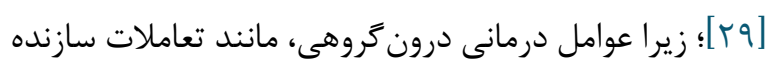

${ }^{1}$ National Institute for Health and Care Excellence (NICE) 


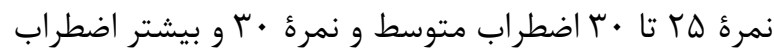

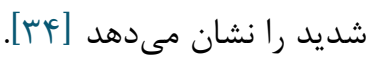

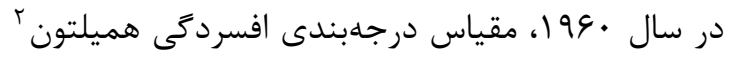

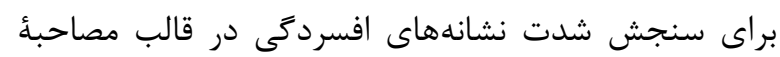

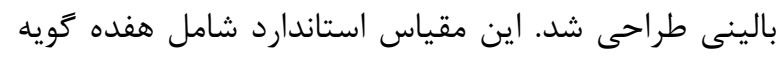

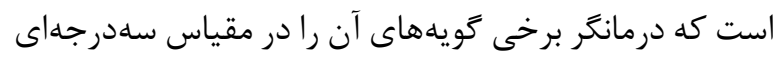

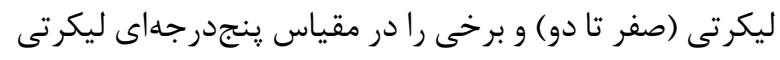
(صفر تا جهار) ازطريق مصاحبه با بيمار تكميل مى كنداند.

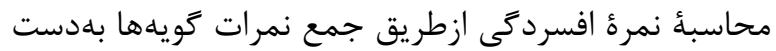

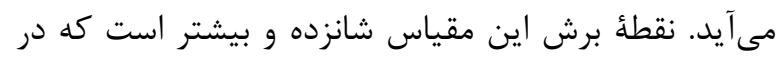

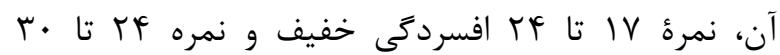

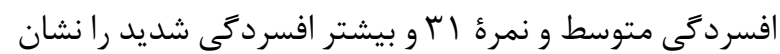

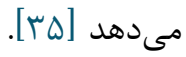

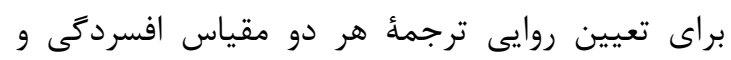
اضطراب هميلتون، دو نفر از يزوهشكران مسلط به زبه زبان انخليسى آن را به فارسى ترجمه (Forward) و سيس

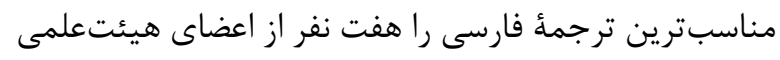
دانشكاه علوم يزشكى مشهد با CVR=•/AF و

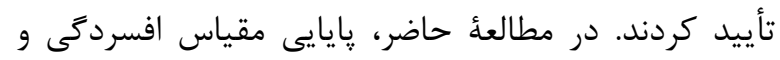

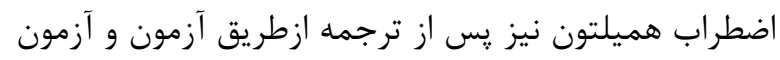

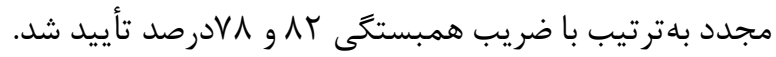

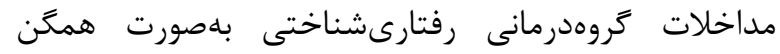

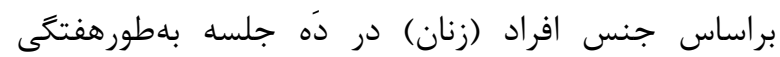

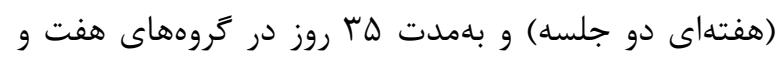

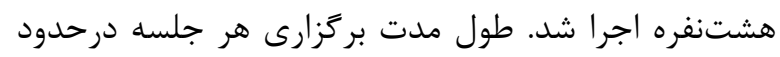

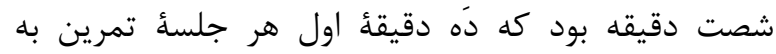

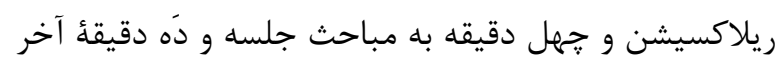
به جمعبندى نتايج تعلق داشت. كروهدرمانى رفتارى شناختى براساس موضوعات مربوط بـاته

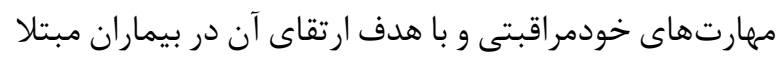

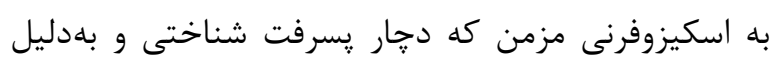

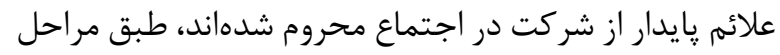

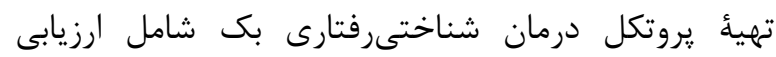

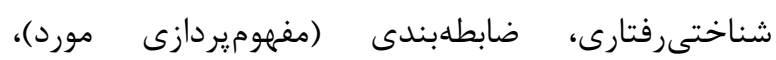

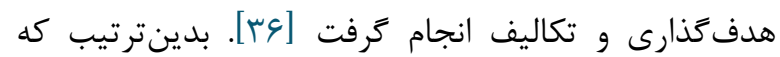

نمونههاى يزوهش حاضر بلهورت تصادفى به دو گروه

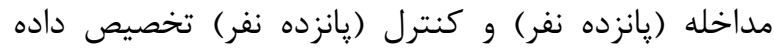

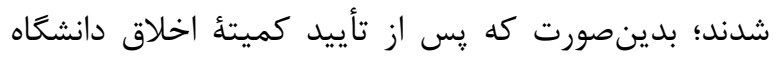

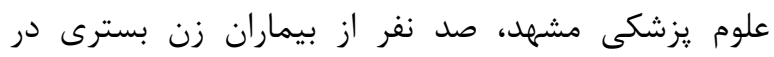
بيمارستان روانيزشكى حجازى در مشهد ازطريق يروندههاى بسترى آنان بلهورت دردسترس ثبتنام شدند. شايان ذكر درئر

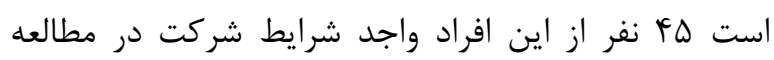

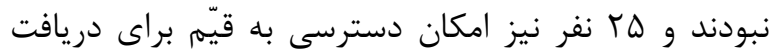

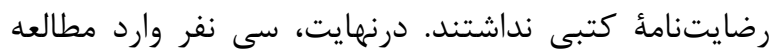

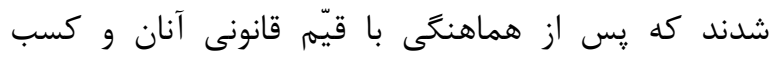

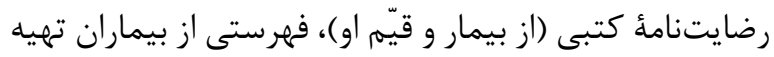

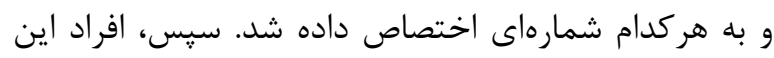

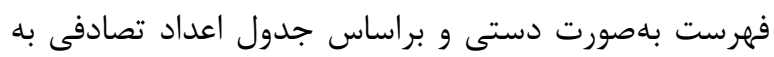
دو كروه مداخله و كنترل تقسيم شدند.

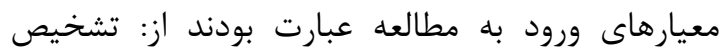

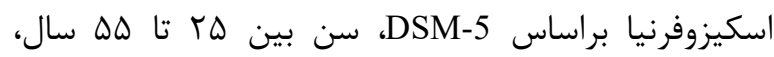

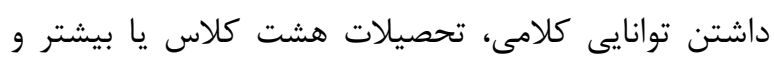

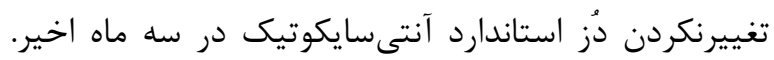

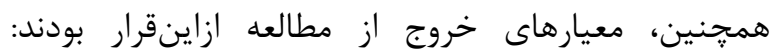

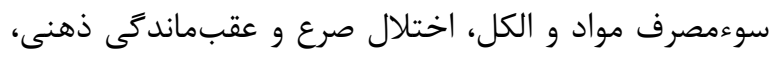

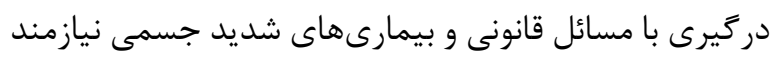

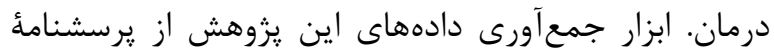

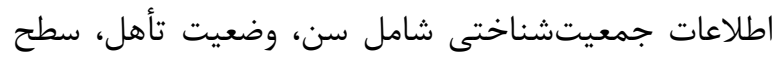
تحصيلات و طول مدت بسترى در بيمارستان و مقياس وضعيت تاهي سطعل

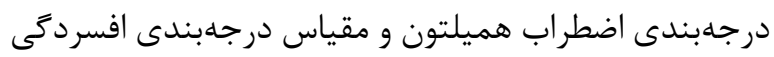
هاميلتون تشكيل مىشد.

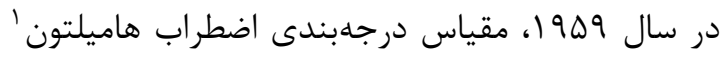
طراحى شد. اين مقياس استاندارد شامل جهارده كويه است إست

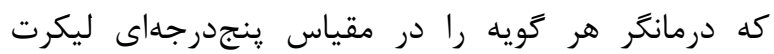

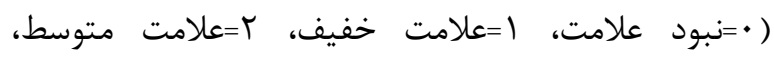
r=علامت شديد و r=علامت خيلى شديد) ازطريق مصاحبه

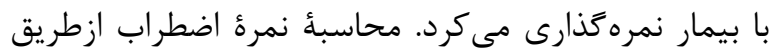

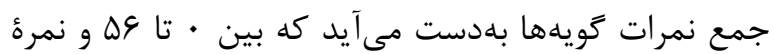

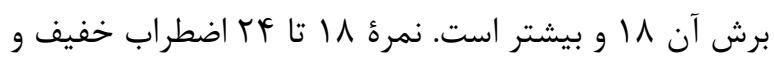

\footnotetext{
${ }^{1}$ Hamilton Anxiety Rating Scale (HARS)

${ }^{2}$ Hamilton Rating Scale for Depression (HRSD)
} 
(REC.1397.298.) شامل كسب موافقتنامئ كتبى از كميتهٔ

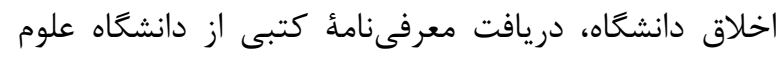

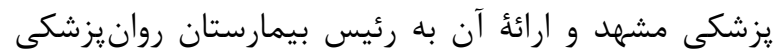

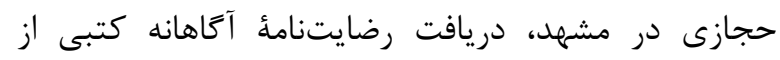

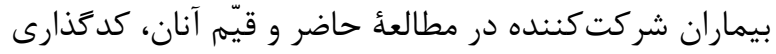

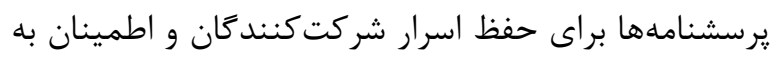

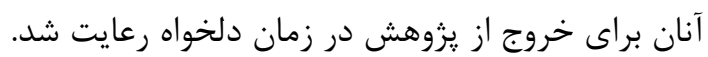

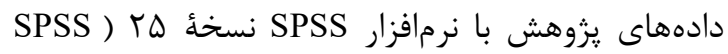
تجزيهوتحليل شد. براى توزيع (Inc., Chicago, IL., USA

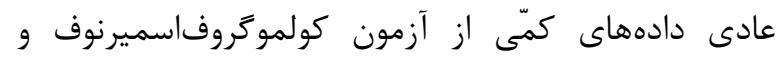

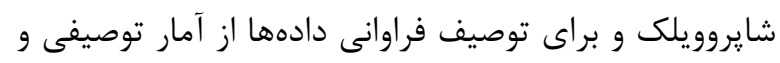

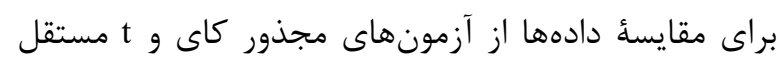

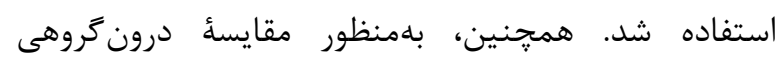

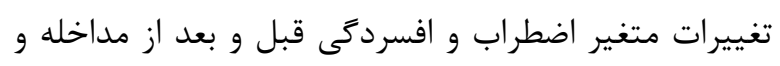

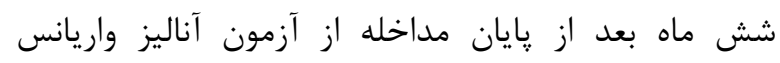

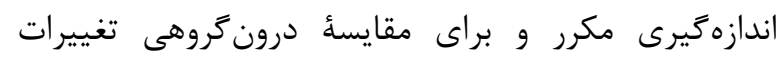

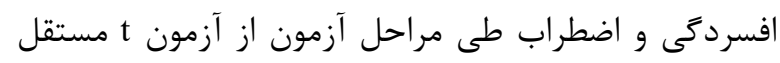

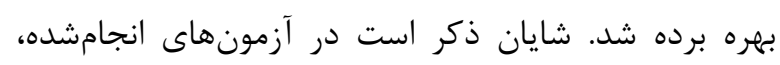

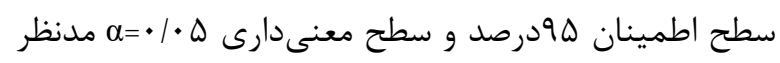

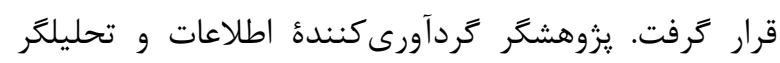

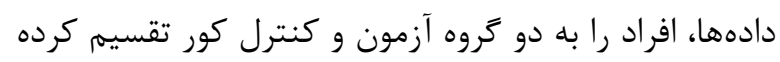

بودند.
فهرستى از مهارتهاى شناختىرفتارى اوليه و موردنياز

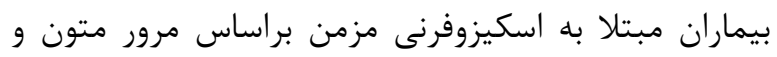

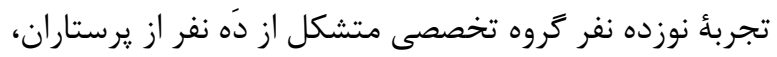

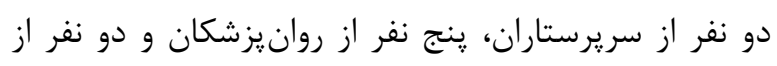
روانشناسان بالينى تهيه و طراحى شد كه در تماس مستقيم

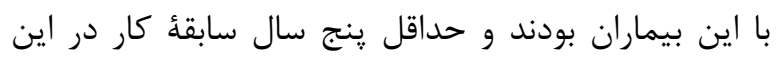
بيمارستان را داشتند. فهرست يادشده شامل وضعيت لباس يوشيدن، وضعيت تغذيه و غذاخوردن، وضعيت نظافت محيط، وضعيت نظافت

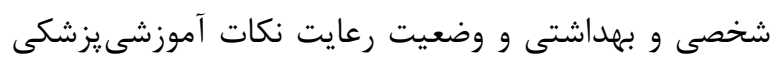

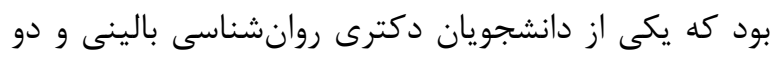

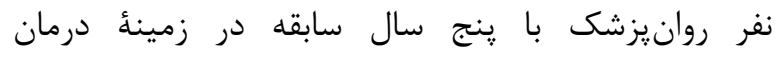

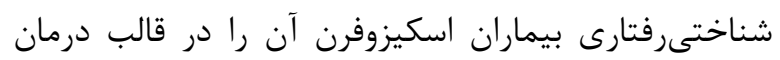

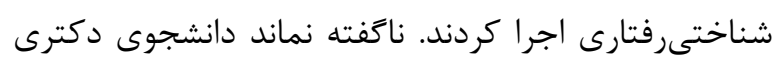

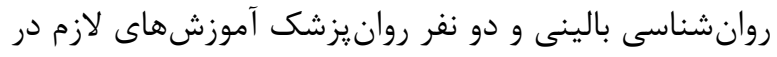

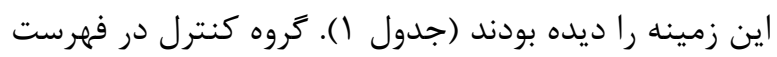

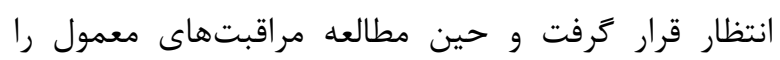

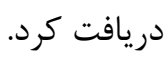

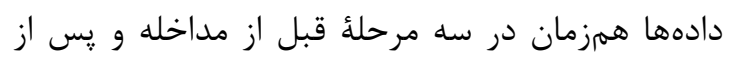

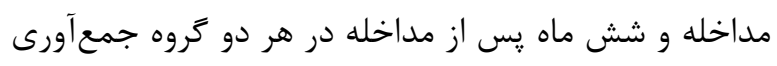

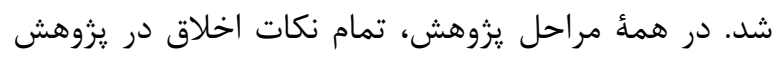

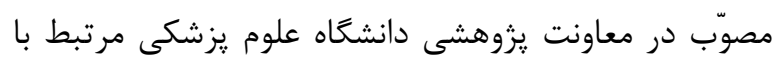

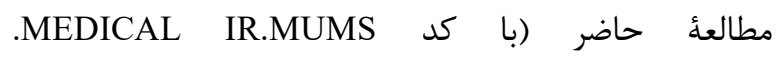

جدول ا. جلسات تروهدرمانى شناختىرفتارى

\section{محتوا}

جلسه

تمرين ريلاكسيشن، بررسى و بهجالشكشيدن شرايط وضعيت لباس پوشيدن و يوشاى بيماران در بخش، جمعبندى و نتيجه گيرى كلى يايان جلسه. جلسة اول تمرين ريلاكسيشن، جمعآورى تكاليف جلسهُ قبلى كه بهصورت مرور ذهنى و نوشتارى بود، بحث درباره تكاليف، جمعبندى و نتيجه گيرى كلى گايان جلسه جلسئ دوم تمرين ريلاكسيشن، بررسى و بهجالش كشيدن شرايط وضعيت تغذيه و غذا خوردن بيماران در بخش، جمعبندى و نتيجه كيرى كلى پايان جلسه جلسؤ سوم تمرين ريلاكسيشن، جمعآورى تكاليف جلسةٔ قبل كه بلصورت مرور ذهنى و نوشتارى بود، بحث درباره تكاليف،

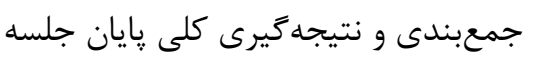


تمرين ريلاكسيشن، بررسى و بهجالش كشيدن وضعيت نظافت محيط بيماران در بخش، جمعبندى و نتيجه كيرى كلى بايان جلسه جلسأ ينجم تمرين ريلاكسيشن، جمعآورى تكاليف جلسؤ قبل كه بهصورت مرور ذهنى و نوشتارى بود، بحث دربارءٔ تكاليف، جمعبندى و نتيجه كيرى كلى پايان جلسه

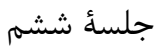
تمرين ريلاكسيشن، بررسى و بهجالش كشيدن وضعيت نظافت شخصى و بهداشتى بيماران در بخش، جمعبندى

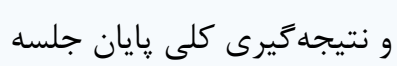
جلسهٔ هفتم تمرين ريلاكسيشن، جمعآورى تكاليف جلسؤ قبل كه بلهورت مرور ذهنى و نوشتارى بود، بحث درباره تكاليف، جمعبندى و نتيجه كيرى كلى پايان جلسئ جلسؤ هشتم تمرين ريلاكسيشن، بررسى و بهجالشكشيدن وضعيت رعايت نكات آموزشى، يزشكى بيماران در بخش،

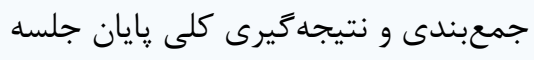
جلسأ نهم تمرين ريلاكسيشن، جمعآورى تكاليف جلسؤ قبل كه بهصورت مرور ذهنى و نوشتارى بود، بحث دربارءٔ تكاليف، جمعبندى و نتيجه گيرى كلى بايان جلسه

جلسةٔ دهم

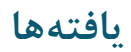

اندازميرى مكرر نشان داد كه در گروه كنترل ازنظر تغييرات

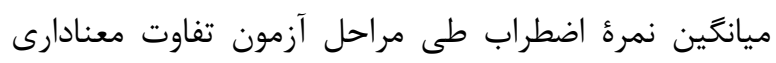

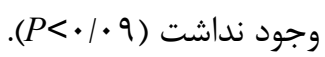

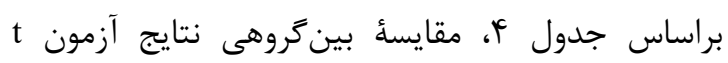

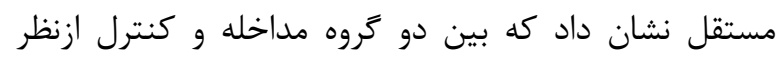

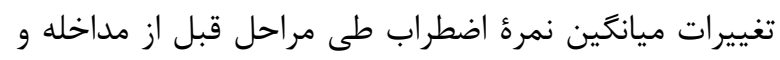

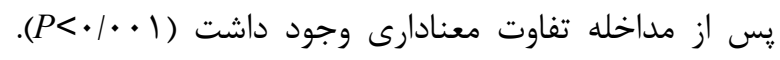
باوجوداين، بين دو كروه مداخله و كنترل ازنظر تغييرات

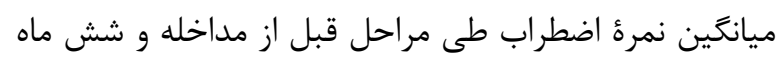

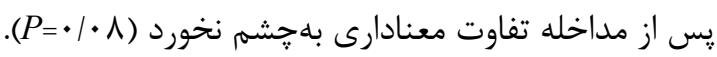
طبق جدول rا، مقايسٔ درون خروهى نتايج آزمون آناليز

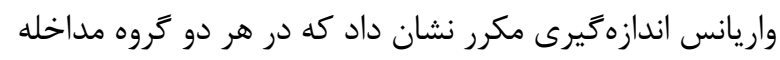

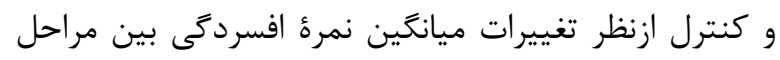

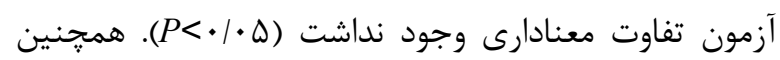

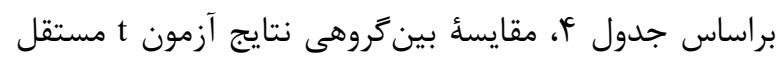

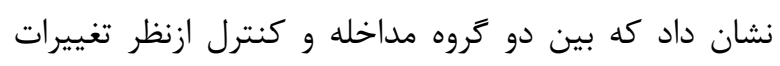

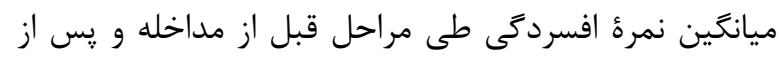

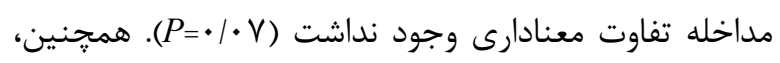

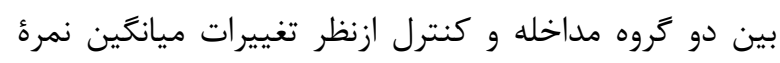

در اين مطالعه، حجم نمونهُ نهايى سى نفر از بيماران زن

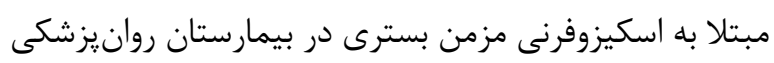

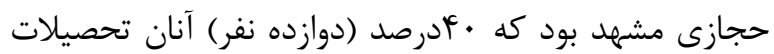

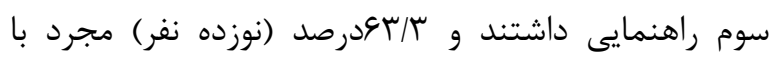

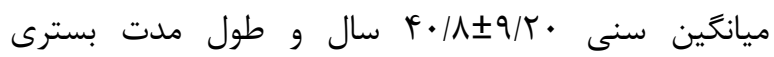

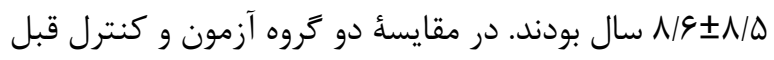
از مداخله، ازنظر اطلاعات جمعيتشناختى بيماران مبتلا به به ديه

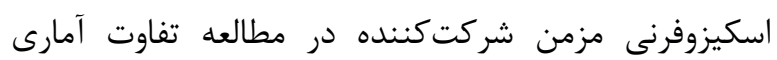

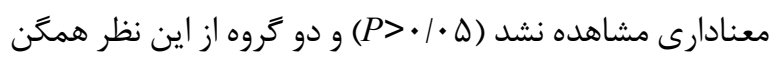

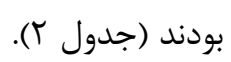

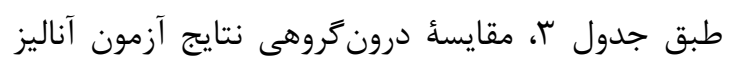

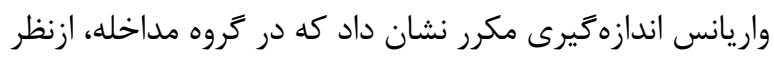

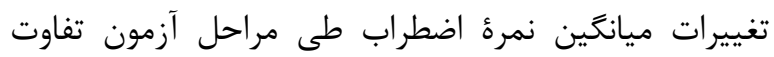

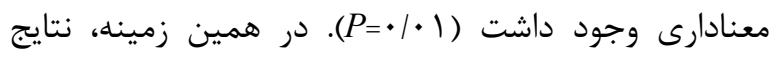

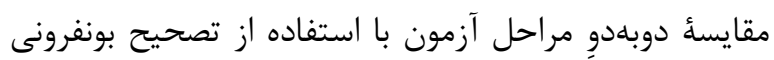

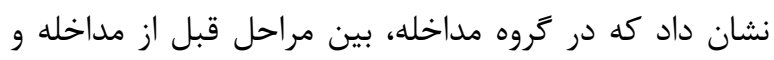

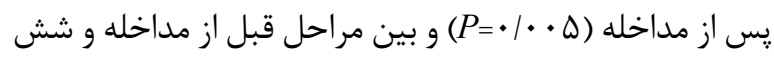

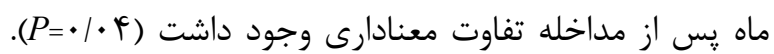
باينحال، در مقايسأ درون گروهى نتايج آزمون آناليز واريانس 
افسردگى شش ماه يس از مداخله تفاوت معنادارى ديده نشد

جدول r. مشخصات جمعيتشناختى زنان بيمار مبتلا به اسكيزوفرنى مزمن در دو كروه مداخله و كنترل

\begin{tabular}{|c|c|c|c|c|}
\hline P-value & (درصد) تعداد & (درصد) تعدل & كروه & متغير \\
\hline \multirow{3}{*}{$* P=\cdot / r \mid$} & $\Lambda(\Delta \Gamma / \Gamma)$ & $\mid r(\Lambda \cdot / \cdot)$ & زيردييلم & \multirow{3}{*}{ سطح تحصيلات } \\
\hline & $\Delta(Y M / Y)$ & $r(T \cdot / \cdot)$ & دييلم & \\
\hline & $r(\mid r / F)$ & $\cdot(\cdot / \cdot)$ & تحصيلات دانشگاهى & \\
\hline \multirow{3}{*}{$P=\cdot /$ ^\ } & $1 \cdot(\notin 9 / V)$ & $9(9 \cdot 1 \cdot)$ & مجرد & \multirow{3}{*}{ وضعيت تأهل } \\
\hline & $r(T \cdot / \cdot)$ & $F(\Gamma \varphi \mid \varphi)$ & متأهل & \\
\hline & $r(1 \Gamma / \Gamma)$ & $r(\mid r / \Psi)$ & مطلقه & \\
\hline \multirow{3}{*}{$* P=\cdot \mid q \mu$} & $\Delta(\Psi \Psi / \Psi)$ & $r(T \cdot / \cdot)$ & r & \multirow{3}{*}{ سن (سال) } \\
\hline & $\Lambda(\Delta \Gamma / \Gamma)$ & $q(F \cdot 1 \cdot)$ & ع تا هـ & \\
\hline & $r(\mid r / Y)$ & $q(\xi \cdot / \cdot)$ & $\Delta \Delta$ \& $\Delta$ & \\
\hline \multirow{3}{*}{$* P=\cdot|\wedge|$} & $1 \cdot(99 / 9)$ & $1 \cdot(99 / 9)$ & 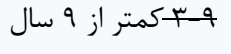 & \multirow{3}{*}{ مدت بسترى (سال) } \\
\hline & $f(Y G / V)$ & $r(r \cdot / \cdot)$ & •ا تا ها. & \\
\hline & $I(G / V)$ & $r(\mid r / F)$ & بيشتر از 19 & \\
\hline
\end{tabular}

*

جدول س. نتايج مقايسهُ درونَروهى اضطراب و افسردَى در زنان مبتلا به اسكيزوفرنى مزمن در دو تروه مداخله و كنترل

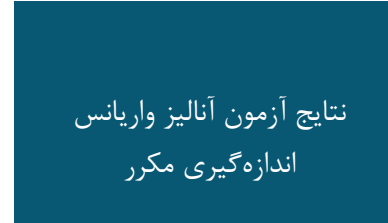

$\mathrm{f}(\mid r / q \mu, I / \mathcal{F})=q / \Lambda \Lambda$

$$
P=\cdot / \cdot 1
$$

$\mathrm{Eta}=\cdot / \mathrm{Fr}$

$f(1 \wedge \cdot r)=r / r$

$P=\cdot / \cdot 9$

$\mathrm{Eta}=\cdot / \mathrm{T}$

$\mathrm{f}(\mid \mathrm{Q} / \Lambda \cdot, 1 / \cdot 1)=1 / 99$

$$
P=\cdot / 4 r
$$

$\mathrm{Eta}=\cdot 119$ $r \Delta / V \cdot \pm 11 / \cdot \Delta$

$r q / \cdots \pm 9 / 91$

$\mu F / \mathcal{F} \cdot \pm \mu / \Lambda q$

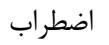

$r r / \Lambda \cdot \pm \Delta / \Delta q$

$m p / q \cdot \pm|r / q|$

$/ / 1 \cdot \pm ه / 99$

$f \cdot / r \cdot \pm q / 19$

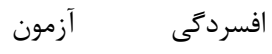


$\mathrm{f}(\mathrm{r}, \mathrm{M})=\mathrm{Q} / \mathrm{Tr}$

$P=\cdot / \cdot \Delta F$

$\mathrm{Eta}=\cdot / \mathrm{r}$

جدول F. مقايسة بينَّروهى افسردَى و اضطراب در بيماران مبتلا به اسكيزوفرنى مزمن در دو عروه مداخله و كنترل

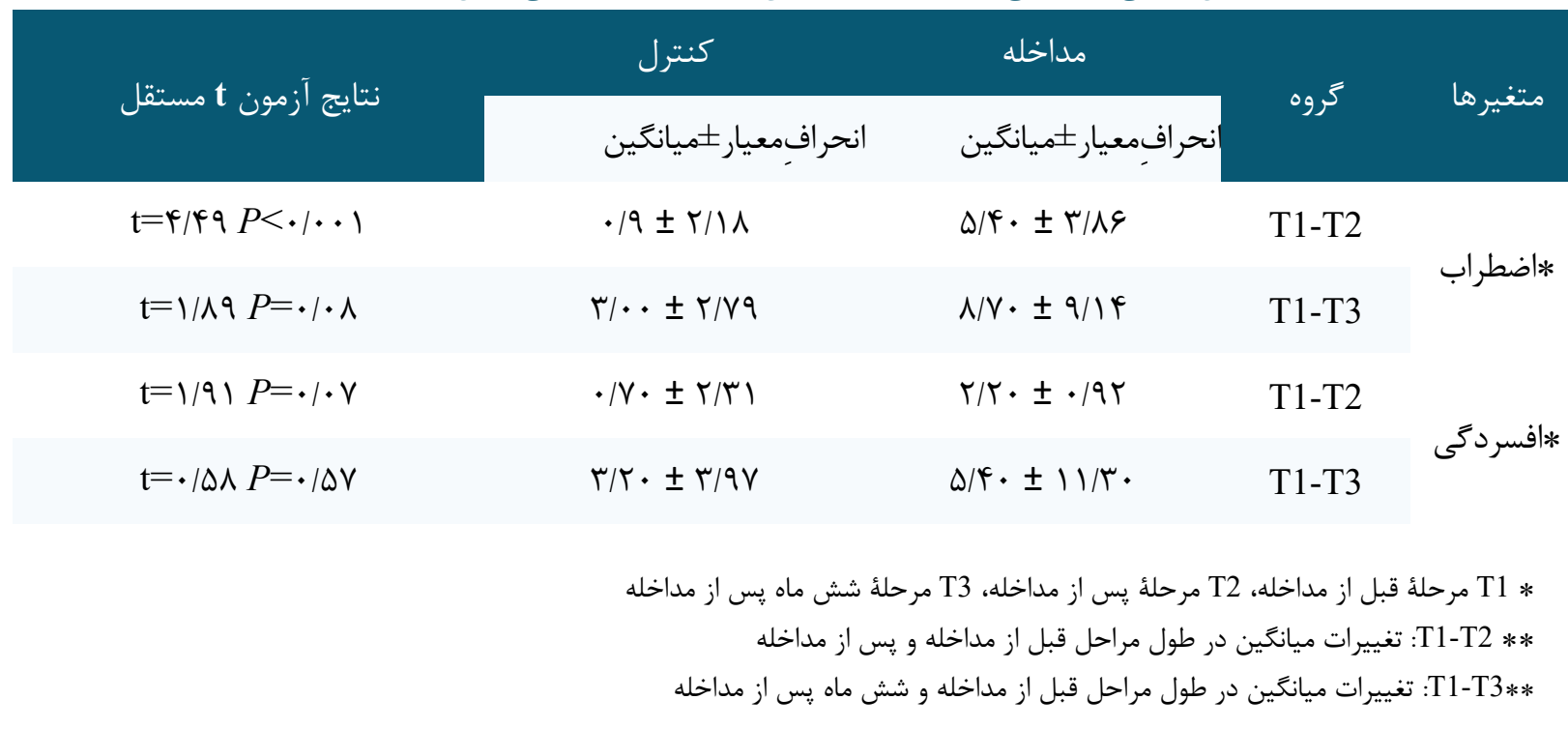

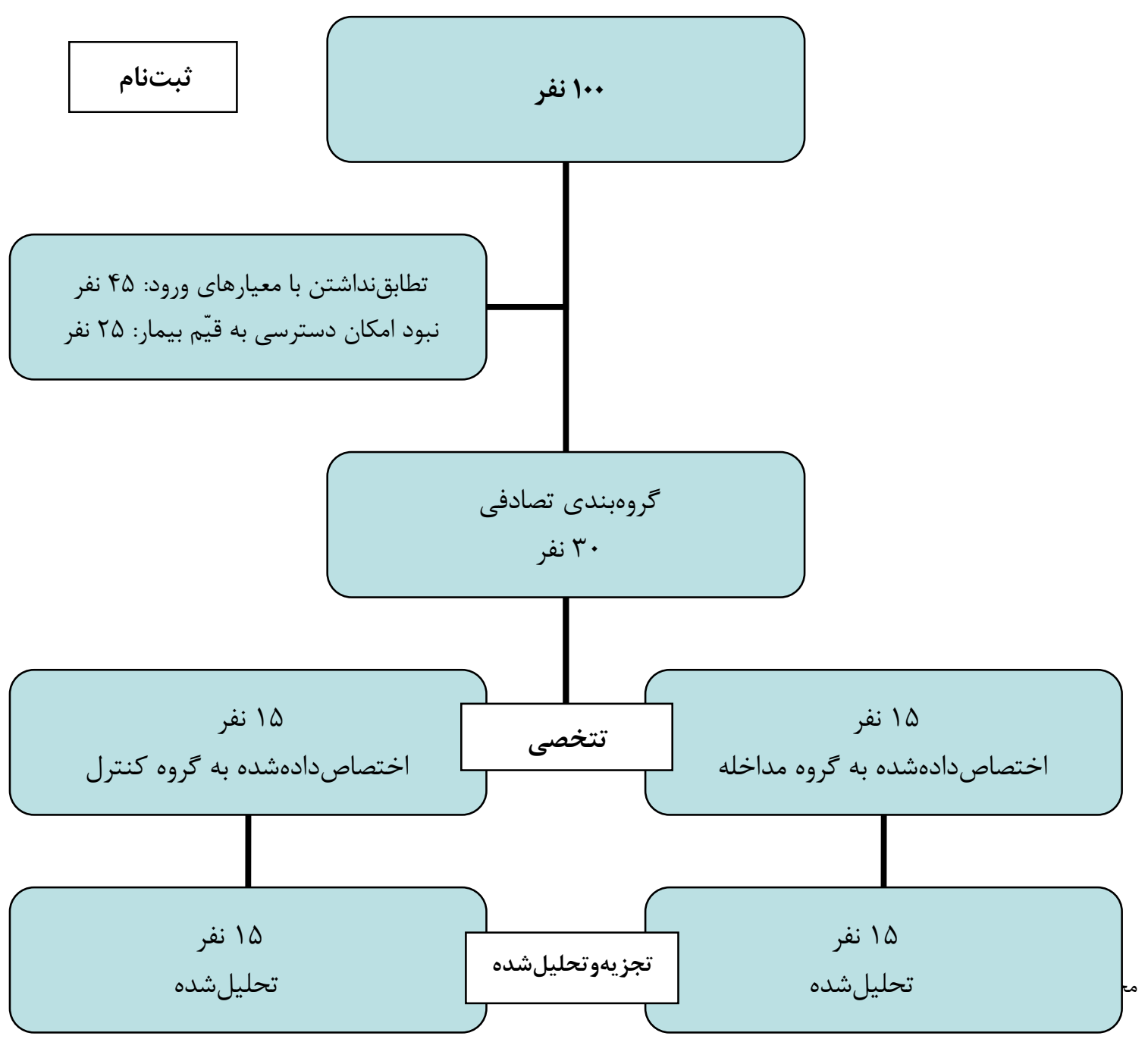


كاهش اضطراب مؤثر باشد؛ اما طى مرحلة شش ماه يس از مداخله بر اضطراب مؤثر نيست.

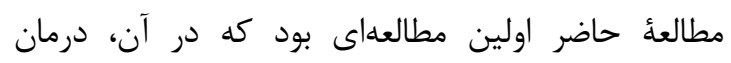

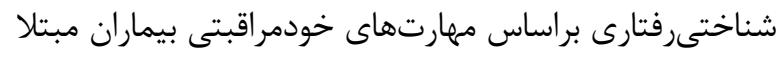
به اسكيزوفرنى مزمن طراحى شده بود كه نتايج آن با بان نتايج

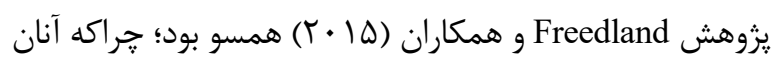

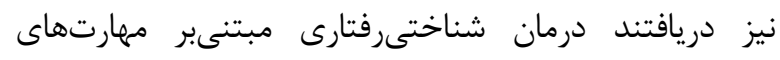

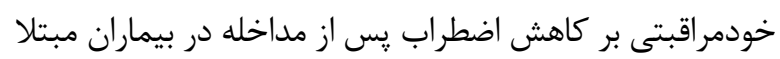

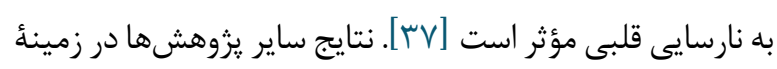

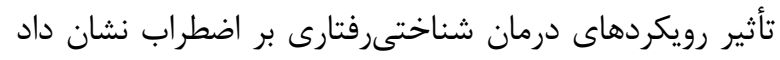

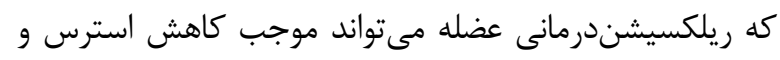

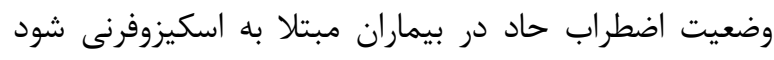

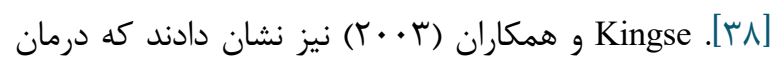

هدف از انجام مطالعهُ حاضر تعيين تأثير گروهدرمانى

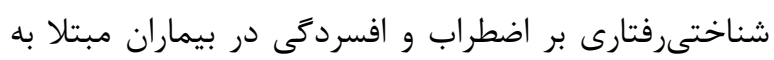

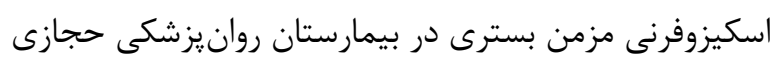

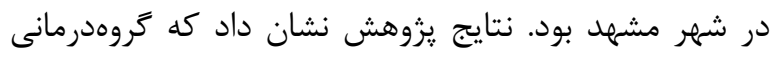

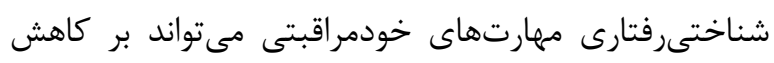

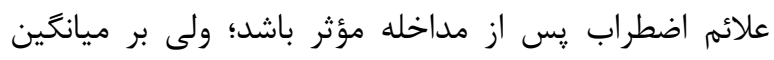

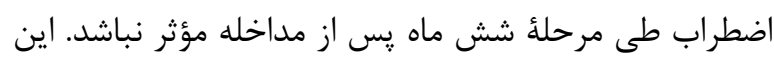

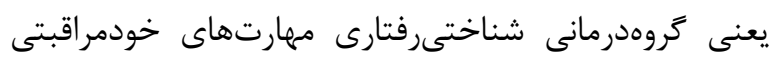

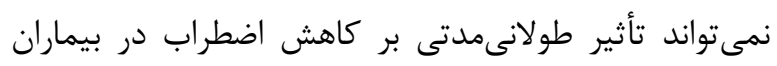

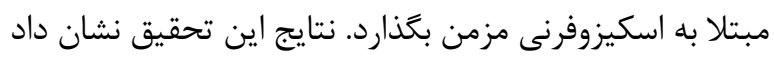

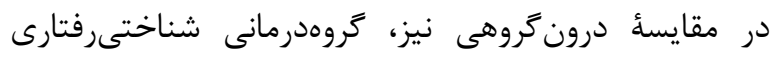

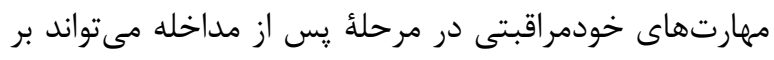


كروهدرمانى شناختىرفتارى مهارتهاى خودمراقبتى بر تغييرات

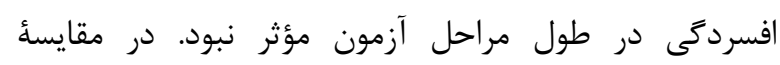

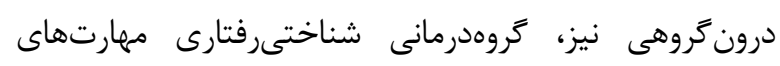

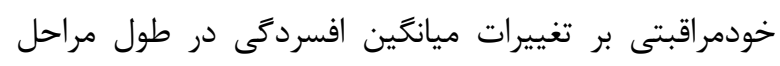

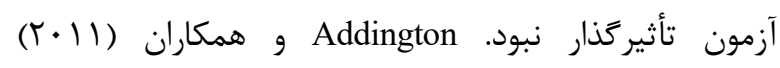

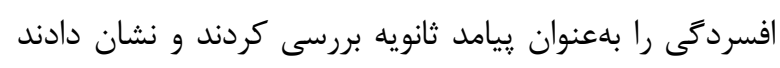

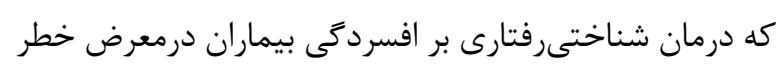

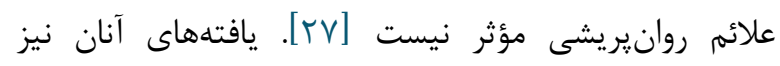

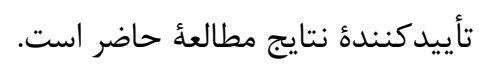
ضعف خودمراقبتى در بيماران مبتلا به اسكيزوفرنى ممكن إنى

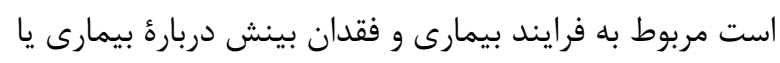

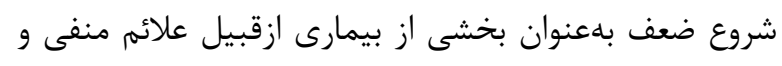

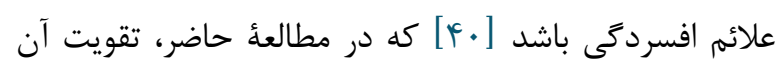

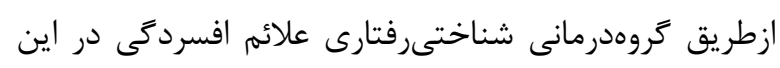

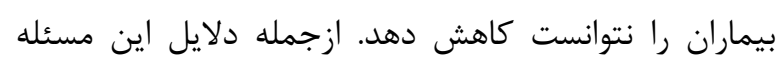

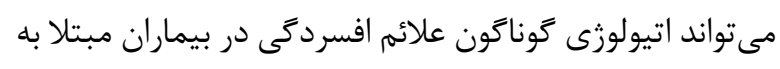
اسكيزوفرنى باشد كه ممكن است شامل خصوصيات علائم روانيريشى (ازقبيل هذيان كزند و آسيب و توهمات شنون استوايى)

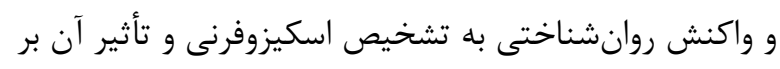

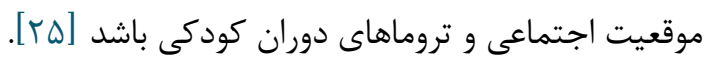

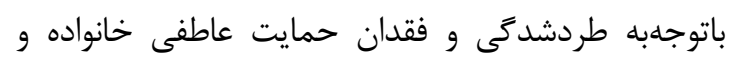

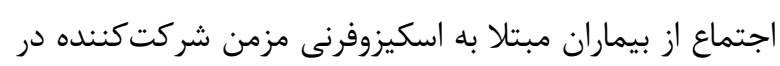

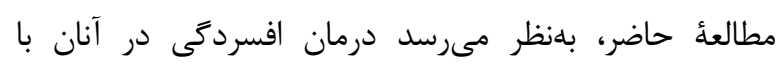

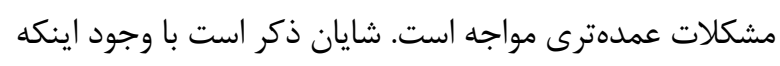

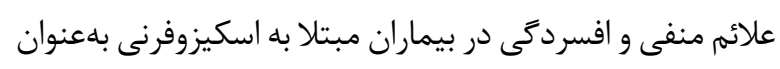

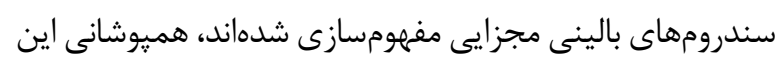

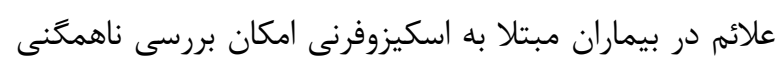

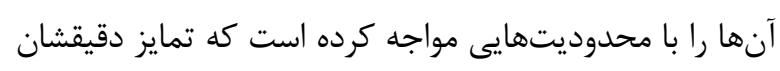

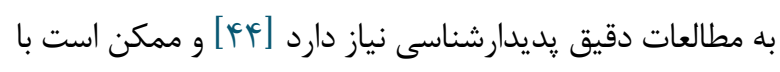
اطلاعات يرسشنامهاى استخر اجيذير نباشد.

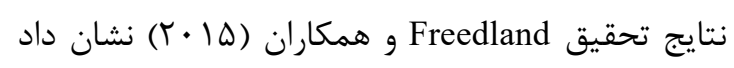

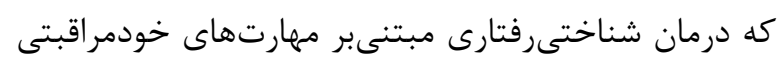

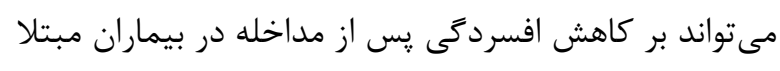

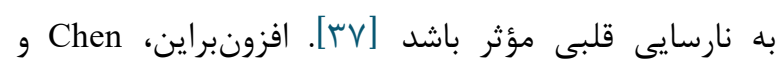

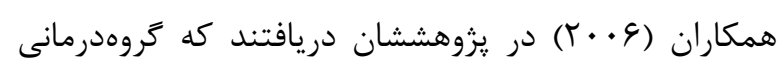

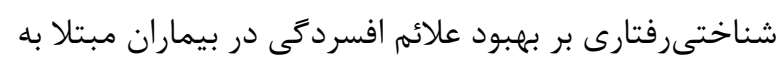

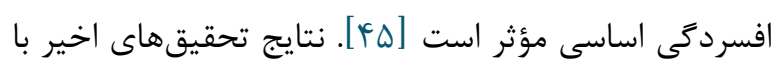

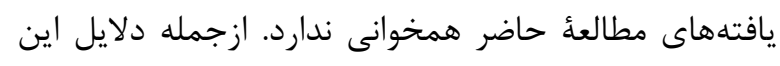

شناختىرفتارى مى تواند موجب كاهش علائم اضطراب اجتماعى إخى

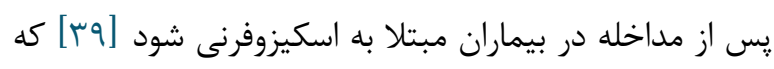
تأييدكننده نتايج مطالعهٔ حاضر است.

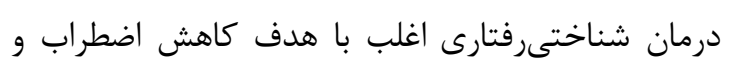

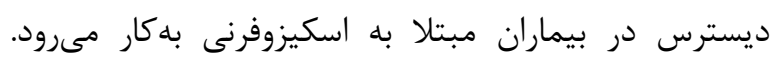

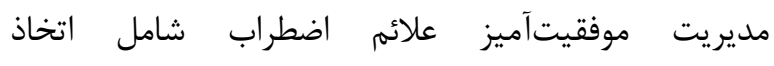

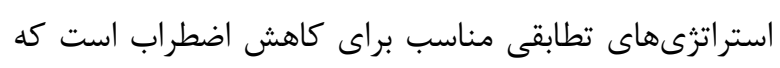

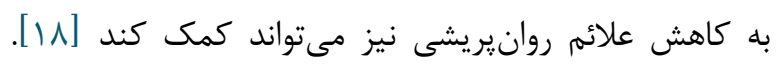

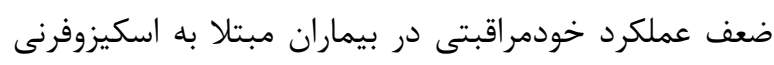

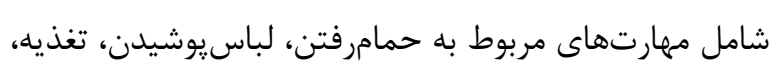

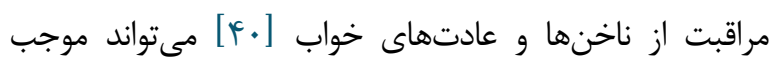

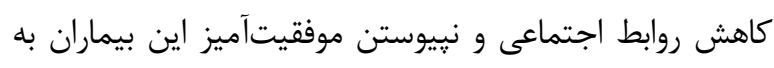

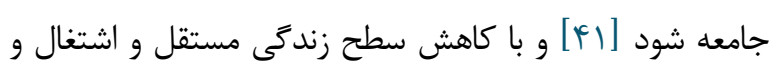

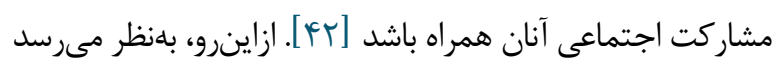

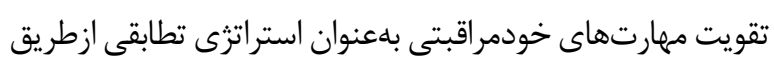

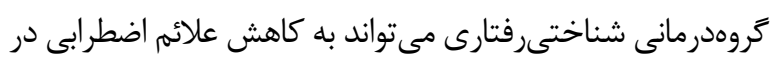
بيماران مبتلا به اسكيزوفرنى مزمن كمكى كنداند

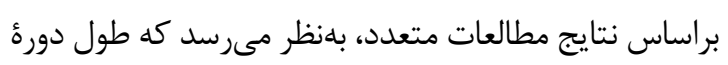

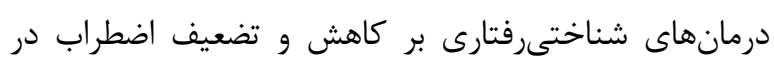

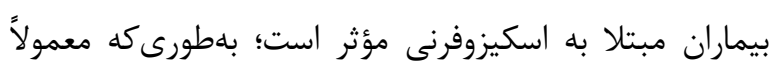

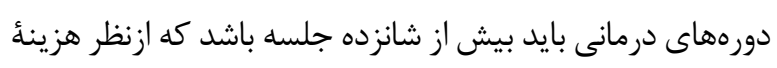

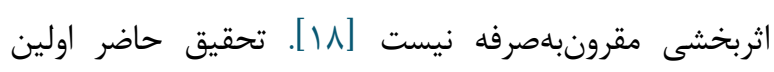

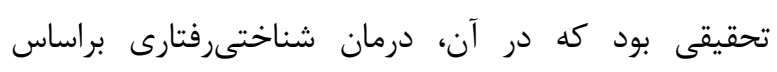

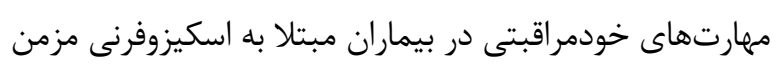

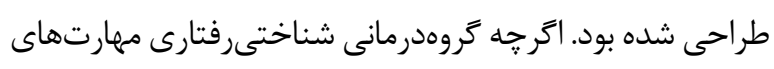

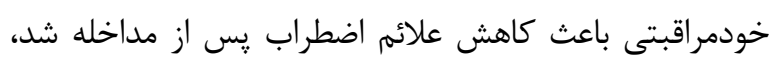

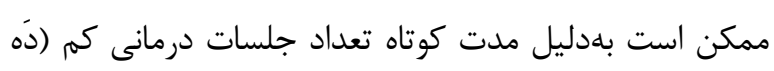

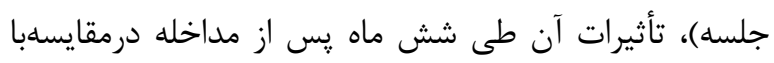
كروه كنترل تداوم پييدا نكند. Eric

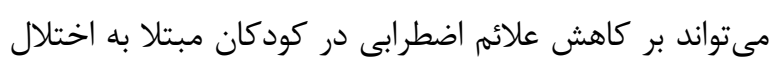

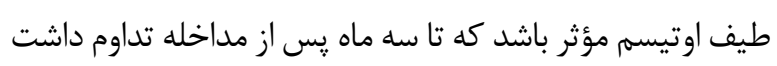

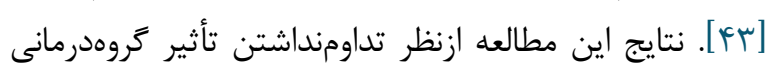

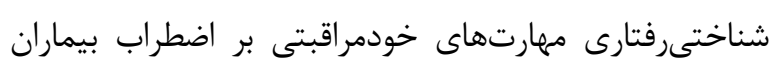

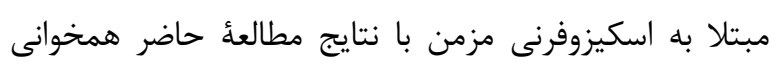

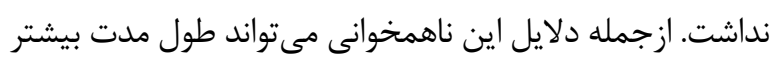

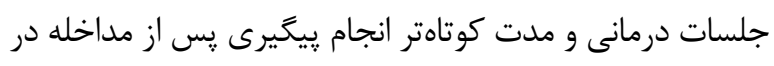

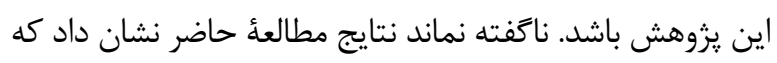




$$
\text { سياسگَزارى }
$$

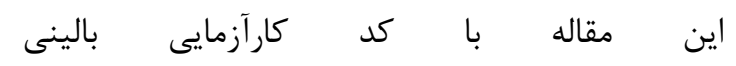
IRCT20180817040818N1 شد كه ع Fمردادوس I با كد يزوهشى دانشگاه علوم :يزشكى مشهد بلهتصويب رسيد.

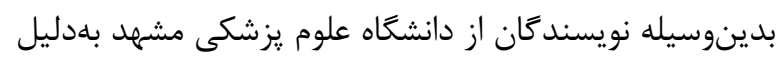
تأمين اعتبار اين تحقيق و مسئولان و يرستاران و سريرستاران محترم بيمارستان روانيزشكى حجازى و نيز شركت كنيند أنان در مطالعه بهخاطر همكارى صميمانهشان قدردانى مى كنند.

\section{سهمم نويسند أنان}

سحر سعيدى اصل: نغارش اوليئ مقاله و تهيئ بِيشنويس

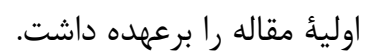

فاطمه السادات رباطى: بخش تجزيهوتحليل آمارى دادهها

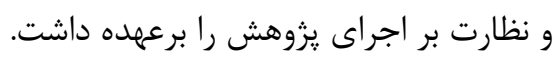

\section{تعارض در منافع}

بين نويسندگان هيجزونه تعارضى در منافع وجود ندارد

$$
\text { منابع مالى }
$$

منابع مالى اين مطالعه توسط نويسندكان تامين شده است.

\section{References}

1. Orrico-Sánchez A, López-Lacort M, Muñoz-Quiles C, Sanfélix-Gimeno G, Díez-Domingo J. Epidemiology of schizophrenia and its management over 8-years period using real-world data in Spain. BMC Psychiatry. 2020;20:1-9. [DOI:10.1186/s12888-020-02538-8] [PMID] [PMCID]

2. Kanchanatawan B, Sirivichayakul S, Thika S, Ruxrungtham K, Carvalho AF, Geffard M, et al. Physiosomatic symptoms in schizophrenia: association with depression, anxiety, neurocognitive deficits and the tryptophan catabolite pathway. Metab Brain Dis. 2017;32(4):1003-16. [DOI:10.1007/s11011-017-9982-7] [PMID]

3. Sun MM, Yang LM, Wang Y, Feng X, Cui KY, Liu LF, et al. BDNF Val66Met polymorphism and
ناهمخوانى مى تواند وضعيت شناختى متفاوت علائم افسردگى در بيماران مبتلا به افسردگى اساسى و بيماران مبتلا به نارسايى قلبى درمقايسهبا بيماران اسكيزوفرنى مزمن باشد.

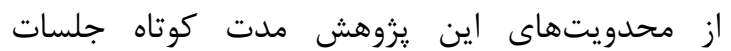

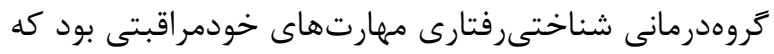
باتوجهبه هزينهُ اثربخشى و محدويت زمانى، افزايش تعداد جلسات براى يزوهشگران مقرونبهصرفه نبود. علاوهبراين،

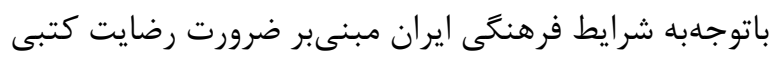

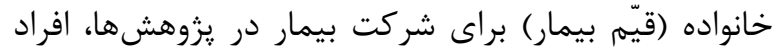
زيادى از شركت در مطالعه محروم شدند؛ زيرا خانوادهها افراد

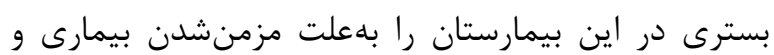

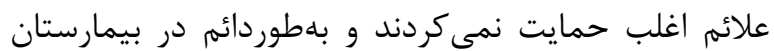

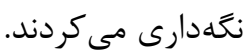

$$
\text { نتيجه كَيرى }
$$

نتايج يزوهش حاضر نشان داد كه گروهدرمانى شناختى رفتارى مىتواند موجب كاهش علائم اضطرابى در زنان مبتلا

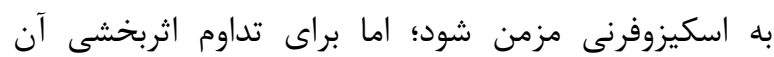
ييشنهاد مىشود تعداد جلسات افزايش داده شود. افزونبراين، نتايج نشان داد كه گروهدرمانى شناختى رفتارى نمى تودواند علائم

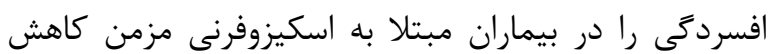

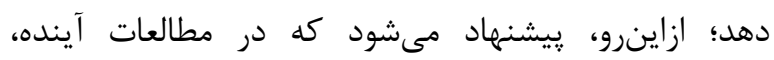

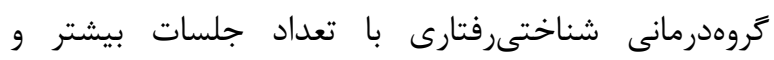
مصاحبههاى بالينى يديدارشناسى براى علائم افسردگى و وركى اضطراب بيماران مبتلا به اسكيزوفرنى طراحى شود.

anxiety/depression symptoms in schizophrenia in a Chinese Han population. Psychiatr Genet. 2013;23(3):124-9. [DOI:10.1097/YPG.0b013e328360c866] [PMID]

4. Kaplan B, Sadock vA, Ruiz P. Synopsis of Psychiatry Behavioral Sciences/ Clinical Psychiatry. Tehran: Arjmand; $2015.827 \mathrm{p}$

5. Ghalehbandi MF. Textbook of Clinical Psychiatry \& Behavioral Sciences. Tehran: Arjmand; 2017. 760 p

6. Gannon JM, Brar J, Rai A, Chengappa KNR. Effects of a standardized extract of Withania somnifera (Ashwagandha) on depression and anxiety symptoms in persons with schizophrenia participating in a randomized,

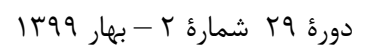

$$
\text { مجله مراقبت يرستارى و مامايى ابنسينا }
$$




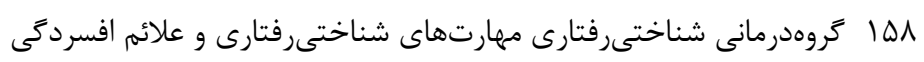

placebo-controlled clinical trial. Ann Clin Psychiatry. 2019;31(2):123-9.

7. Chiang YH, Beckstead JW, Lo SC, Yang CY. Association of auditory hallucination and anxiety symptoms with depressive symptoms in patients with schizophrenia: A three-month follow-up. Arch Psychiatr Nurs. [DOI:10.1016/j.apnu.2018.03.014] [PMID] 2018;32(4):585-90.

8. Kay SR, Fiszbein A, Opler LA. The positive and negative syndrome scale (PANSS) for schizophrenia. Schizophr Bull. 1987;13(2):261-76. [DOI:10.1093/schbul/13.2.261] [PMID]

9. Pallanti S, Cantisani A, Grassi G. Anxiety as a core aspect of schizophrenia. Curr Psychiatry Rep. 2013;15(5):354. [DOI:10.1007/s11920-013-0354-7] [PMID]

10. Tsai YF, Chen CY. Self-care symptom management strategies for auditory hallucinations among patients with schizophrenia in Taiwan. Appl Nurs Res. 2006;19(4):191-6. [DOI:10.1016/j.apnr.2005.07.008] [PMID]

11. Kanchanatawan B, Thika S, Sirivichayakul S, Carvalho AF, Geffard M, Maes M. In Schizophrenia, Depression, Anxiety, and Physiosomatic Symptoms Are Strongly Related to Psychotic Symptoms and Excitation, Impairments in Episodic Memory, and Increased Production of Neurotoxic Tryptophan Catabolites: a Multivariate and Machine Learning Study. Neurotox Res. 2018;33(3):641-55. [DOI:10.1007/s12640-018-9868-4] [PMID]

12. Kanchanatawan B, Sirivichayakul S, Carvalho AF, Anderson G, Galecki P, Maes M. Depressive, anxiety and hypomanic symptoms in schizophrenia may be driven by tryptophan catabolite (TRYCAT) patterning of IgA and IgM responses directed to TRYCATs. Prog NeuroPsychopharmacol Biol Psychiatry. 2018;80:205-16. [DOI:10.1016/i.pnpbp.2017.06.033] [PMID]

13. Braga RJ, Reynolds GP, Siris SG. Anxiety comorbidity in schizophrenia. Psychiatry Res. 2013;210(1):1-7. [DOI:10.1016/j.psychres.2013.07.030] [PMID]

14. Tsai J, Rosenheck RA. Psychiatric comorbidity among adults with schizophrenia: A latent class analysis. Psychiatry Res. 2013;210(1):16-20. [DOI:10.1016/j.psychres.2013.05.013] [ [PMCID]

15. Hou C-L, Ma X-R, Cai M-Y, Li Y, Zang Y, Jia F-J, et al. Comorbid moderate-severe depressive symptoms and their association with quality of life in Chinese patients with schizophrenia treated in primary care. Community Ment Health J. 2016;52(8):921-6. [DOI:10.1007/s10597016-0023-5] [PMID]

16. Temmingh H, Stein DJ. Anxiety in Patients with Schizophrenia: Epidemiology and Management. CNS Drugs. 2015;29(10):819-32. [DOI:10.1007/s40263-0150282-7] [PMID]

17. Rahim T, Rashid R. Comparison of depression symptoms between primary depression and secondary-toschizophrenia depression. Int J Psychiatry Clin Pract.
2017;21(4):314-7.

[DOI:10.1080/13651501.2017.1324036] [PMID]

18. Howells FM, Kingdon DG, Baldwin DS. Current and potential pharmacological and psychosocial interventions for anxiety symptoms and disorders in patients with schizophrenia: structured review. Hum Psychopharmacol. 2017;32(5). [DOI:10.1002/hup.2628] [PMID]

19. Chen SR, Chien YP, Kang CM, Jeng C, Chang WY. Comparing self-efficacy and self-care behaviours between outpatients with comorbid schizophrenia and type 2 diabetes and outpatients with only type 2 diabetes. J Psychiatr Ment Health Nurs. 2014;21(5):414-22. [DOI:10.1111/ipm.12101] [PMID]

20. Donato K. Self-Care as a Burdened Virtue. Episteme. 2017;28(1):3.

21. Rathod S, Phiri P, Kingdon D. Cognitive behavioral therapy for schizophrenia. Psychiatr Clin North Am. 2010;33(3):527-36. [DOI:10.1016/j.psc.2010.04.009] [PMID]

22. Laws KR, Darlington N, Kondel TK, McKenna PJ, Jauhar S. Cognitive Behavioural Therapy for schizophrenia - outcomes for functioning, distress and quality of life: a meta-analysis. BMC Psychol. 2018;6(1):32. [DOI:10.1186/s40359-018-0243-2] [PMID] [PMCID]

23. Jones C, Hacker D, Xia J, Meaden A, Irving CB, Zhao S, et al. Cognitive behavioural therapy plus standard care versus standard care for people with schizophrenia. Cochrane Database Syst Rev. 2018;12:CD007964. [DOI:10.1002/14651858.CD008712.pub3] [PMCID]

24. Opoka SM, Lincoln TM. The Effect of Cognitive Behavioral Interventions on Depression and Anxiety Symptoms in Patients with Schizophrenia Spectrum Disorders: A Systematic Review. Psychiatr Clin North Am. [DOI:10.1016/j.psc.2017.08.005] [PMID]

25. Upthegrove R, Marwaha S, Birchwood M. Depression and Schizophrenia: Cause, Consequence, or Transdiagnostic Issue? Schizophr Bull. 2017;43(2):240-4.

26. Lodha P, De Sousa A. Cognitive Behavioural Therapy and Its Role in the Outcome and Recovery from Schizophrenia. Schizophrenia Treatment Outcomes: Springer; 2020. p. 299-312 [DOI:10.1007/978-3-03019847-3 26]

27. Addington J, Epstein I, Liu L, French P, Boydell KM, Zipursky RB. A randomized controlled trial of cognitive behavioral therapy for individuals at clinical high risk of psychosis. Schizophr Res. 2011;125(1):54-61. [DOI:10.1016/j.schres.2010.10.015] [PMID]

28. Bible LJ, Casper KA, Seifert JL, Porter KA. Assessment of self-care and medication adherence in individuals with

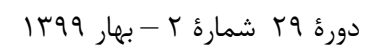$$
\text { مجله مراقبت يرستارى و مامايى ابنسينا }
$$ 
mental health conditions. J Am Pharm Assoc (2003). 2017;57(3S):S203-S10 [DOI:10.1016/j.japh.2017.02.023] [PMID]

29. Orfanos S, Banks C, Priebe S. Are Group Psychotherapeutic Treatments Effective for Patients with Schizophrenia? A Systematic Review and MetaAnalysis. Psychother Psychosom. 2015;84(4):241-9. [DOI:10.1159/000377705] [PMID]

30. Sadock BJ, Sadock VA, Ruiz P. Synopsis of psychiatry: behavioral sciences. New York: Wolters Kluwer; 2015.

31. Halperin S, Nathan P, Drummond P, Castle D. A cognitive-behavioural, group-based intervention for social anxiety in schizophrenia. Aust N Z J Psychiatry. 2000;34(5):809-13.

[DOI:10.1080/j.1440$\underline{\text { 1614.2000.00820.x }] \text { [PMID] }}$

32. Kunikata H, Yoshinaga N, Nakajima K. Effect of cognitive behavioral group therapy for recovery of selfesteem on community-living individuals with mental illness: Non-randomized controlled trial. Psychiatry Clin Neurosci. 2016;70(10):457-68. [DOI:10.1111/pen.12418] [PMID]

33. Penn DL, Meyer PS, Evans E, Wirth RJ, Cai K, Burchinal M. A randomized controlled trial of group cognitivebehavioral therapy vs. enhanced supportive therapy for auditory hallucinations. Schizophr Res. 2009;109(13):52-9. [DOI:10.1016/j.schres.2008.12.009] [PMID]

34. Hamilton $\mathrm{M}$. The assessment of anxiety states by rating. $\mathrm{Br} J$ Med Psychol. 1959;32(1):50-5. [DOI:10.1111/j.2044-8341.1959.tb00467.x] [PMID]

35. Hamilton M. A rating scale for depression. J Neurol Neurosurg Psychiatry. 1960;23(1):56-62. [DOI:10.1136/jnnp.23.1.56] [PMID] [PMCID]

36. Hawton K. Cognitive behaviour therapy for psychiatric problems (a practical guide). Tehran: Arjmand; 1989.

37. Freedland KE, Carney RM, Rich MW, Steinmeyer BC, Rubin EH. Cognitive Behavior Therapy for Depression and Self-Care in Heart Failure Patients: A Randomized Clinical Trial. JAMA Intern Med. 2015;175(11):1773-82. [DOI:10.1001/jamainternmed.2015.5220] [PMID] [PMCID]

38. Vancampfort D, De Hert M, Knapen J, Maurissen K, Raepsaet J, Deckx S, et al. Effects of progressive muscle relaxation on state anxiety and subjective well-being in people with schizophrenia: a randomized controlled trial. Clin Rehabil. 2011;25(6):567-75. [DOI:10.1177/0269215510395633] [PMID]

39. Kingsep P, Nathan P, Castle D. Cognitive behavioural group treatment for social anxiety in schizophrenia. $\begin{array}{lll}\text { Schizophr } & \text { Res. } & \text { 2003;63(1-2):121-9. }\end{array}$ [DOI:10.1016/S0920-9964(02)00376-6]

40. Baruah A, Bhaduri A, Deuri S. Effect of psychoeducative intervention on knowledge about illness and self-care in patients with schizophrenia. Nurs J India. 2012;103(4):188.
41. Hsu Y-C, Lin W-Q, Kuo H-W. Schizophrenic Patients' Poor Perception in Personal Hygiene. Ment Health Fam Med. 2017;13(1):369-74. [DOI:10.25149/17568358.1301006]

42. Ayres H, Ngo H, John AP. Limited changes in activities of daily life performance ability among people with schizophrenia at clinical settings and the factors moderating the changes. Schizophr Res: Cognition. 2019;16:29-35. [DOI:10.1016/j.scog.2018.12.001] [PMID] [PMCID]

43. Storch EA, Arnold EB, Lewin AB, Nadeau JM, Jones AM, De Nadai AS, et al. The effect of cognitivebehavioral therapy versus treatment as usual for anxiety in children with autism spectrum disorders: A randomized, controlled trial. J Am Acad Child Adolesc $\begin{array}{lll}\text { Psychiatry. } & \text { 2013;52(2):132-42. }\end{array}$ [DOI:10.1016/j.jaac.2012.11.007] [PMID]

44. Krynicki CR, Upthegrove R, Deakin J, Barnes TR. The relationship between negative symptoms and depression in schizophrenia: a systematic review. Acta Psychiatr Scand. 2018;137(5):380-90. [DOI:10.1111/acps.12873] [PMID]

45. Chen T-H, Lu R-B, Chang A-J, Chu D-M, Chou K-R. The evaluation of cognitive-behavioral group therapy on patient depression and self-esteem. Arch Psychiatr Nurs. 2006;20(1):3-11. [DOI:10.1016/j.apnu.2005.08.005] [PMID]

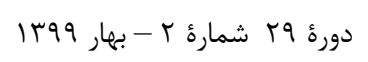

